\title{
Effects of Mindfulness-Based Interventions on Self-compassion in Health Care Professionals: a Meta-analysis
}

\author{
Rachel S. Wasson ${ }^{1}$ (i) $\cdot$ Clare Barratt $^{1} \cdot$ William H. O'Brien $^{1}$ \\ Published online: 5 March 2020 \\ (C) Springer Science+Business Media, LLC, part of Springer Nature 2020
}

\begin{abstract}
Objectives Health care professionals have elevated rates of burnout and compassion fatigue which are correlated with poorer quality of life and patient care, and inversely correlated with self-compassion. Primary studies have evaluated the extent to which mindfulness-based interventions increase self-compassion with contradictory findings. A meta-analytic review of the literature was conducted to quantitatively synthesize the effects of mindfulness-based interventions on self-compassion among health care professionals.

Methods Twenty-eight treatment outcome studies were identified eligible for inclusion. Five cumulative effect sizes were calculated using random-effects models to evaluate differences of changes in self-compassion for treatment and control groups. Within and between group comparisons were evaluated. Sub-group and moderator analyses were conducted to explore potential moderating variables.

Results Twenty-seven articles $(k=29, N=1020)$ were utilized in the pre-post-treatment meta-analysis. Fifteen samples $(52 \%)$ included health care professionals and fourteen (48\%) professional health care students. Results showed a moderate effect size between pre-post-treatment comparisons $(g=.61,95 \% \mathrm{CI}=.47$ to .76$)$ for self-compassion and a strong effect size for pretreatment to follow-up $(g=.76,95 \% \mathrm{CI}=.41$ to 1.12$)$. The effect size comparing post-treatment versus post-control was moderate. One exploratory moderator analysis was significant, with stronger effects for interventions with a retreat component. Conclusions Findings suggest mindfulness-based interventions improve self-compassion in health care professionals. Additionally, a variety of mindfulness-based programs may be useful for employees and trainees. Future studies with rigorous methodology evaluating effects on self-compassion and patient care from mindfulness-based interventions are warranted to extend findings and explore moderators.
\end{abstract}

Keywords Mindfulness $\cdot$ Self-compassion $\cdot$ Health care professionals $\cdot$ Treatment outcome

Health care professionals, individuals who provide expert caregiving services to others, have emotionally demanding careers and high rates of emotional exhaustion, compassion fatigue, and burnout. They experience exposure to human suffering and death, and interact with challenging patients, families, and co-workers on a regular basis. Simultaneously,

Electronic supplementary material The online version of this article (https://doi.org/10.1007/s12671-020-01342-5) contains supplementary material, which is available to authorized users.

Rachel S. Wasson

rwasson@bgsu.edu

1 Department of Psychology, Bowling Green State University, 822 E Merry Ave, Bowling Green, OH 43403, USA health care professionals must perform their job tasks efficiently, accurately, and ethically (Dyrbye et al. 2005; Lee et al. 2009; Murphy et al. 2009; Regehr et al. 2014; Stewart et al. 1997). Many health care professionals also struggle with fluctuating and long work hours, insurance difficulties, changing workplace roles, and low staffing (Regehr et al. 2014; Rutledge et al. 2009; Stucky et al. 2009; Wallace et al. 2009). Given these factors, it comes as no surprise that this population is particularly susceptible to stress (Aiken et al. 2002).

Stress in health care professionals is a serious concern because it can adversely affect their mental health, quality of life, and job performance (Galantino et al. 2005; McVicar 2003; Spickard Jr et al. 2002). Stress is also correlated with reduced ability to establish strong relationships with patients (Pastore et al. 1995), which is a critical component to positive 
therapeutic outcomes. Thus, health care professionals experiencing high levels of stress may deliver sub-optimal patient care and are more likely to make medical errors (Leiter et al. 1998; Shanafelt et al. 2002; Vahey et al. 2004; Williams et al. 2007).

Furthermore, prolonged stress is a precursor to burnout. Burnout is a syndrome of emotional exhaustion, excessive stress, loss of meaning in work, feelings of ineffectiveness, and a tendency to view people as objects rather than people (Maslach et al. 1996). A 2014 survey of 6880 US physicians found a $54.4 \%$ prevalence rate of burnout (Shanafelt et al. 2015). Moreover, Shanafelt et al. (2012) found burnout to be more common among physicians relative to the general US working population. Similar to stress outcomes, these high rates of burnout in health care professionals are important because they are correlated with poorer mental health, quality of life, and quality of patient care (Brazeua et al. 2010; Poghosyan et al. 2010; Rosen et al. 2006; Shanafelt and Dyrbye 2012; Verdon et al. 2008).

In addition to stress and burnout, health care professionals can also experience compassion fatigue. Compassion is when one experiences feelings of concern for another who is suffering, coupled with the desire to help alleviate their suffering (Klimecki and Singer 2012). The other-oriented essence of compassion promotes prosocial behavior. Compassion fatigue is characterized by a reduced capacity for compassion (Klimecki and Singer 2012). Arising from repetitive and intense exposure to persons experiencing trauma and suffering, compassion fatigue is thought of as a form of secondary traumatic stress. Similar to Post-Traumatic Stress Disorder, compassion fatigue is characterized by intrusive thoughts of patient suffering and trauma, chronic physiological activation, and avoidance of interactions where suffering is involved (Cocker and Joss 2016; Gallagher 2013). This reduction of compassion is of concern for health care professionals because it may adversely affect their ability to be sensitive, nonjudgmental, and respectful to patients (Gilbert 2005; Wiklund Gustin and Wagner 2013).

The construct of compassion is related, yet distinct from empathy (Klimecki and Singer 2012). Empathy refers to sharing the same feeling as the suffering person and usually occurs prior to feelings of compassion. However, empathetic distress is self-oriented and involves being overwhelmed by experiencing the emotion of the sufferer, often leading to withdrawal behavior (Klimecki and Singer 2012). For health care professionals, it is important to encourage a compassionate response and reduce compassion fatigue to allow them to continue engaging in prosocial helping behaviors to aid their patients and clients. With this skill intact, they can acknowledge the suffering of their clients and care for them, without being overwhelmed by the painful emotions themselves.

Given the negative consequences of stress, burnout, and compassion fatigue among health care professionals, it is critical to identify ways to prevent or reduce their occurrence and severity. One promising area of research is focused on self-compassion. The construct of self-compassion originates in Buddhist philosophy and was defined by Neff (2003) as three interconnected components: mindfulness, self-kindness, and common humanity. Self-compassion involves the employment of these three components during times of pain, failure, and difficulty. Mindfulness skills are particularly important because they promote an enhanced present-moment awareness and a willingness to experience emotions with openness, curiosity, and acceptance. Self-kindness refers to letting go of judgment and criticism, and employing kindness toward the self. Finally, common humanity is the concept that other human beings experience difficulties in life which can help prevent self-pity, isolation, and feelings of shame. The Self-Compassion Scale (SCS) was developed by Neff in 2003 and assesses the positive and negative aspects of these three main self-compassion components: mindfulness versus overidentification, self-kindness versus self-judgment, and common humanity versus isolation. This measure has demonstrated adequate construct and convergent validity (Neff 2003), and the SCS-Short Form has shown good test-retest reliability and internal consistency ( $\alpha=.87$; Raes et al. 2011).

Self-compassion is distinct from the construct of mindfulness. Both constructs involve turning one's awareness toward their inner experiences with an accepting stance (Neff and Dahm 2015). However, the general mindfulness construct focuses on paying attention to any experience, not exclusively painful ones. Additionally, self-compassion includes elements of self-kindness and common humanity, which may or may not occur through mindfulness alone. Furthermore, mindfulness practice focuses on the internal experience while selfcompassion emphasizes the "experiencer" of the suffering (Neff and Dahm 2015).

Since the development of the SCS, research on the construct of self-compassion and correlates has expanded. Within the general population, findings indicate that individuals who are more self-compassionate tend to report less burnout, anxiety, depression, shame, and fear of failure, and greater life satisfaction, social connectedness, emotional intelligence, and happiness (Barnard and Curry 2011; Mills et al. 2007; Neff et al. 2005; Neff et al. 2007a; Williams et al. 2008). Self-compassion has also been positively correlated with positive affect and negatively correlated with negative affect, emotional exhaustion, and shame (Barnard and Curry 2011; Leary et al. 2007; Neff et al. 2007b; Neff and Vonk 2009). Additionally, self-compassion has been found to be negatively correlated with rumination (Neff 2003).

Given the breadth of this literature, MacBeth and Gumley (2012) conducted a meta-analysis on the association between self-compassion and psychopathology. The study examined 20 samples reporting data from 4007 participants. Most of the participants were students, with health care professionals 
accounting for about $5 \%$ of the total. They found that selfcompassion was inversely correlated with stress $(r=-.54$, $p<.0001)$, depression $(r=-.52, p<.0001)$, and anxiety symptoms $(r=-.51, p<.0001)$. Finally, higher levels of self-compassion have been associated with higher levels of empathic concern, altruism, perspective-taking, and forgiveness of others, all desirable traits in health care professionals (Neff and Pommier 2013). Overall, there is considerable evidence that higher levels of self-compassion are associated with positive aspects of well-being and inversely correlated with negative constructs.

Self-compassion is an important skill for health care professionals because it allows them to maintain their emotional sensitivity to patients. Self-compassion provides the health care professional in-the-moment self-care to alleviate personal empathetic distress and, therefore, proceed with compassionate care (Neff and Germer 2018). Preliminary research supports the relationship of higher self-compassion and overall positive variables of well-being in health care professionals (Beaumont et al. 2016a). Some promising early research in this area includes the recent cross-sectional survey of 213 health care professionals (Kemper et al. 2015). They reported that self-compassion was inversely correlated with sleep difficulties $(r=-.27, p<.01)$, and positively correlated with resilience $(r=.54, p<.01)$. Similarly, Richardson et al. (2016) reported the results of a cross-sectional survey of 307 medical students and residents indicating that self-compassion significantly and inversely predicted burnout $(\beta=-.375 ; p<.05)$. Finally, Duarte et al. (2016) conducted a cross-sectional study of 280 nurses and found that self-compassion with mindful awareness was associated with lower levels of burnout and compassion fatigue. Based on these findings, selfcompassion may play an important role in reducing burnout symptoms and enhancing well-being among health care professionals. The emerging research on self-compassion highlights the importance of fostering this ability in health care professionals who are particularly vulnerable to burnout, stress, and compassion fatigue.

One way to promote self-compassion in health care professionals may be through training in mindfulness meditation. Mindfulness has been defined as "the awareness that emerges through paying attention on purpose, in the present moment, and nonjudgmentally, to things as they are" (Kabat-Zinn 1994). Mindfulness-based therapies have gone by many different names and forms. The more common contemporary therapies are mindfulness-based stress reduction (MBSR), mindfulness-based cognitive therapy (MBCT), dialecticalbehavioral therapy (DBT), and acceptance and commitment therapy (ACT) - although meditation is not a required component of ACT.

Mindfulness-based interventions share core components that include fostering awareness, increasing present-moment experiences, cultivating response flexibility, and improving affect tolerance. These skills are thought to help individuals become more aware of automatic thinking and acting, interrupt rumination about past experiences and worries about future events, promote "considered action," and learn to allow emotional experiences to rise and fall without behaviorally responding, while simultaneously engaging in more adaptive behaviors. Mindfulness-based therapies can be implemented for individuals, small groups, or at an organizational level.

General mindfulness-based interventions (e.g., MBSR, MBCT) sometimes implicitly communicate components of self-compassion. Other more focused mindfulness interventions such as compassion-focused therapy and mindful selfcompassion explicitly teach self-compassion skills with an emphasis on conveying the importance of being kind to others and oneself during times of difficulty. Interestingly, even though general mindfulness-based interventions do not explicitly teach self-compassion, researchers have argued and demonstrated that self-compassion may be a key mediator to the positive outcomes observed from these types of interventions (Neff and Dahm 2015). For example, Birnie et al. (2010) found that after completing an MBSR intervention, community-sample participants showed an increase in selfcompassion and decreased personal distress, while no significant change was observed in empathic concern.

Researchers have begun to evaluate the effects of mindfulness training on self-compassion among health care professionals. For example, Shapiro et al. (2005) conducted a randomized controlled trial that evaluated an 8-week MBSR program for twenty-eight health care professionals who were randomly assigned to the treatment or a wait-list control group. Shapiro et al. (2005) assessed levels of self-compassion, perceived stress, psychological distress, burnout, and satisfaction with life before and after the intervention. Results showed significant treatment $(n=28)$ versus control $(n=18)$ differences on measures of perceived stress $(F(2,24)=4.4$, $p=.04, d=0.65)$ and self-compassion $(F(2,24)=9.85$, $p=.004, d=0.97)$. Additionally, a separate regression analysis showed that changes in self-compassion significantly predicted positive changes in perceived stress.

Conducting mindfulness-based interventions for timelimited health care professionals is logistically challenging. Obtaining "buy-in" from the organization and employees/ students may take considerable conscious effort to implement an intervention effectively (Byron et al. 2015). Even when health care professionals are invested in a mindfulness-based intervention, work conflicts can often arise and affect attendance and home practice adherence (Luberto et al. 2017). Some studies also revealed nonsignificant changes in selfcompassion among health care professionals participating in similar interventions (e.g., Brooker et al. 2013; Mahon et al. 2017; Romcevich et al. 2018). The current inconsistencies in the intervention methods (e.g., treatment type, length of 
intervention, home practice) and discrepancies in corresponding results throughout the literature make it difficult to draw conclusions about the efficacy of these programs. There is, however, a large enough body of research to conduct a meta-analytic investigation.

A few meta-analyses exist in the current literature that relates to the current investigation. For example, Khoury et al. (2013) conducted a meta-analysis on mindfulness-based therapies and observed moderate to large changes in anxiety, depression, mindfulness, and stress outcomes. Kirby et al. (2017) investigated compassion-based interventions and identified significant changes for compassion, self-compassion, mindfulness, depression, and anxiety. For both studies, the population included was restricted to adults, providing little insight on important demographic variables, such as professions and lifestyles. Burton et al. (2017) conducted a metaanalysis on mindfulness-based intervention focused exclusively on health care professionals. Stress significantly improved; however, the authors noted that the focus on only one outcome was limiting. Burton et al. (2017) emphasized the need for future studies to investigate "dosage" and "active ingredients" in mindfulness-based interventions to help condense these programs to meet the time-limited needs of this population.

The specific aims of this project were to (1) provide a systematic methodological review of the literature on treatment outcome studies evaluating the extent to which mindfulness-based interventions produce change in selfcompassion in health care professionals, (2) calculate the effect sizes associated with mindfulness-based interventions targeting self-compassion among health care professionals, and (3) explore potential moderators of mindfulness-based intervention effect sizes.

\section{Methods}

\section{Article Identification and Selection}

An unstructured review of the literature up until June 2018 was conducted. Informed by the preliminary literature review, the following databases were determined to be relevant to this meta-analysis: PsycINFO, Academic Search Complete, MEDLINE, Psychological and Behavioral Sciences Collection, CINAHL Plus, and Humanities International Complete. The preliminary literature review indicated that the following search terms would provide a sufficiently wide nomological network of variables: mindfulness, mindfulnessbased cognitive therapy, mindfulness-based stress reduction, acceptance and commitment therapy, dialectic behavior therapy, stress management, yoga, meditation, mindfulness-based compassion training, compassion, and self-compassion. All the possible combinations of the intervention and self- compassion variables were used in the literature search with no search constraints.

For the current study, mindfulness-based interventions were defined as any intervention that was based on either (a) a previously established mindfulness-based therapy (e.g., MBSR) or (b) included explicit mindfulness skills training. As explained previously, mindfulness-based interventions have common core components that theoretically translate across intervention types. Health care professional terms were not used in the article search because of the many different terms used to describe this population. By not including these terms, all studies in this area were screened for health care professional participants. We also included students in training who are seeing patients. The purpose of this decision was to include all health care professionals who are providing patient care. Even though the skill levels and experiences vary, burnout and compassion fatigue, which may affect patient care, has been documented across all included participant groups. Overall, the rationale for the wide scope of intervention type and health care professional participants allowed us to gather the most information we could about the possible relationships among interventions and outcomes.

An additional search for articles was conducted by descendency and ascendency through the authors and references, respectively. Authors of articles with insufficient data were contacted via email to request missing information. Finally, a search for articles was conducted of the references section in related review and meta-analysis articles (Chiappetta et al. 2018; Irving et al. 2009; Kirby et al. 2017; Khoury et al. 2013; West et al. 2016).

All potential articles identified in the literature search were evaluated for relevance to this meta-analysis using the following inclusion criteria: (a) a mindfulness-based intervention was provided; (b) the sample included health care professionals (e.g., medical students, medical and psychological trainees, physicians, nurses, psychologists, midwives); (c) an experimental pre-post-design was used to evaluate outcomes; (d) self-compassion was used as an outcome variable; (e) the article was published in an academic journal or dissertation (if full text was available); and (f) the article was written in the English language. Randomized and non-randomized trials were included. Inclusion criteria also required that the study use an explicit quantitative measure of self-compassion, such as the Self-Compassion Scale (SCS; 26 items; Neff 2003) or the SCS-Short Form (SCS-SF; 12 items; Raes et al. 2011).

Articles were evaluated by two independent raters through multiple steps in succession in the following order: title, abstract, and full-text reviews. Studies that explicitly contained rule-out criteria (e.g., book reviews, literature reviews, crosssectional studies, correlational studies) were excluded from further review. All disagreements were discussed and coding rules were updated as necessary. The search results produced 683 articles, all of which were screened for inclusion by two 
independent raters. Cohen's kappa was calculated to determine interrater reliability. The interrater reliability for title selection was $k=.80, p<.0001$ and 206 articles were retained for further review. The interrater reliability for abstract selection was $k=.85, p<.01$ and 74 articles retained for full-text review. At this stage, seven additional articles were identified in a review of references. Both raters reviewed 20 of these 81 articles in order to establish an agreement rate of $95 \%$. The remaining studies were reviewed independently by each coder for full-text review. See Fig. 1 for a flowchart of article selection. Two raters independently coded nineteen data points (i.e., means, standard deviations, effect sizes) from five articles and demonstrated a strong reliability $(k=1.00)$. The remaining data points were coded by one researcher.

\section{Effect Size Calculation and Analyses}

Becker's $d$ was designed to be analogous to the standard treatment-control effect size (Becker 1988). Becker argued that the treatment might affect not only the mean of a sample but also the standard deviation. Thus, the formula used $\mathrm{SD}_{\text {pre- }}$ treatment in the denominator to standardize the difference between pre-treatment and post-treatment means as follows: Becker's $d=M_{\text {post }}-M_{\text {pre }} / \mathrm{SD}_{\text {pre. }}$. Morris and DeShon (2002) established that the denominator of Becker's $d$ should be adjusted by the pre-treatment to post-treatment correlation in order to render a more accurate estimate of the population parameter. Smith and Beretvas (2009) demonstrated that using a pre-treatment-post-treatment correlation-adjusted pooled standard deviation in the denominator was superior to Becker's formula which used only the pre-treatment standard deviation (Smith and Beretvas 2009).

In this investigation, we thus used the effect size formula developed by Morris and DeShon (2002) and recommended by Smith and Beretvas (2009) which is $d_{\mathrm{rm}}=M_{\text {post }}-M_{\text {pre }}$ $\mathrm{SD}_{\text {difference, }}$, where $\mathrm{SD}_{\text {difference }}=\sqrt{ } S d^{2}{ }_{\text {pre }}+\mathrm{SD}_{\text {post }}{ }^{2}$ $2 \mathrm{r}_{\text {prepost }} \mathrm{SD}_{\text {pre }} \mathrm{SD}_{\text {post. }}$. The $d_{\text {rm }}$ was then converted to Hedges $g_{\text {rm }}$ by multiplying it by the standard bias adjustment (Hedges 1982): Hedges $g_{\mathrm{rm}}=d_{\mathrm{rm}} \times(1-3 /(4(n-1)-1))$. The sampling variance of $d_{\mathrm{rm}}$ was then calculated as Variance $d$ $\mathrm{rm}=(1 / n)(n-1 / n-3)\left[1+\left(\mathrm{n} d^{2}{ }_{\mathrm{rm}}\right]-d^{2}{ }_{\mathrm{rm}} /[c(n-1)]^{2}\right.$, where $\mathrm{c}(n-$ $1)=1-\left(3 /(4(n-1)-1)\right.$. Given that the Variance $d_{\mathrm{rm}}$ includes the bias adjustment (i.e., $c(n-1))$, the same value was used as the variance for Hedges $g$ (Smith and Beretvas 2009).

To calculate the $d_{\mathrm{rm}}$ using the formulas above, it was necessary to know the pre-treatment to post-treatment correlation. This statistics is infrequently reported in research articles (Morris and DeShon 2002). Among the studies included in this meta-analysis, none reported the pre-treatment to posttreatment correlation. We were able to impute the pretreatment to post-treatment correlation using alternative data. Our review of all included articles indicated that 9 provided
Fig. 1 Flowchart of article selection

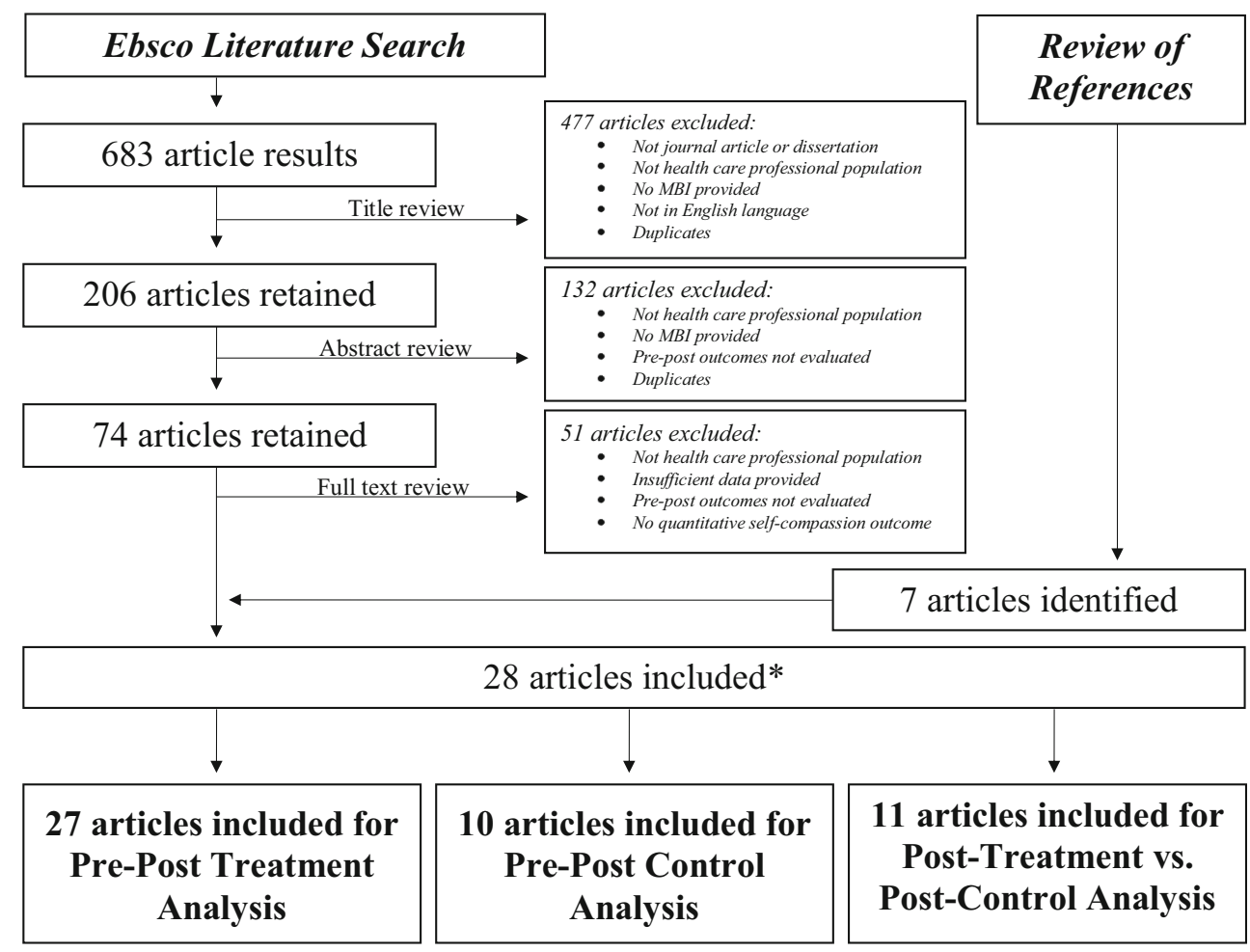

*Articles were utilized in multiple analyses; MBI, mindfulness-based intervention; Ebsco literature search included all databases described in methods section 
pre-post- $t$ test results that could be used to calculate the pretreatment to post-treatment correlation using Morris and DeShon's (2002) two formulas: $\mathrm{SD}_{\text {difference }}=n\left(M_{\text {post }}-\right.$ $\left.M_{\text {pre }}\right)^{2} / t_{\text {pre-post }}^{2}$ and $r=\mathrm{SD}_{\text {pre }}^{2}+\mathrm{SD}_{\text {post }}^{2}-\mathrm{SD}_{\text {difference }} / 2\left(\mathrm{SD}_{\text {pre }}\right.$ $\times \mathrm{SD}_{\text {post }}$. The 9 imputed correlations were then weighted by sample size and a final weighted average pre-treatment to post-treatment correlation of $r=.62$ was calculated. This correlation was then used on all subsequent calculations of effect sizes, effect size variance, and sampling error.

The final cumulative effect sizes, confidence intervals, homogeneity, bias, and fail-safe values were calculated using MetaWin (Rosenberg et al. 2000). A random-effects model was utilized because different health professional samples were used and multiple effects were expected in addition to sampling error. Jamovi version 1.0.5 was used to conduct moderator analyses and to generate forest plots and funnel plots (The Jamovi Project 2019). In all, the following cumulative effect sizes were calculated: pre-post-treatment for treatment groups, pre-post for control groups, pre-treatment to follow-up for treatment groups, pre-post-comparison between treatment and control groups, and treatment versus control group comparisons at post-treatment (note: treatment versus control group comparisons at follow-up were not conducted because there were too few effect sizes). Confidence intervals were generated for all cumulative effect sizes. Heterogeneity of the cumulative effect sizes were evaluated using Qtotal (Huedo-Medina et al. 2006). Since Qtotal can be underpowered with small samples, $I^{2}$ was also calculated (Higgins and Thompson 2002). The formula for $I^{2}$ was [Qtotal $-(k-1) /$ Qtotal $\times 100$. In cases where the Qtotal $<k-1, I^{2}$ was truncated to zero, as recommended by Higgins and Thompson (2002).

Forest plots were generated to illustrate the results of the included samples. Three methods were used to assess publication bias. First, funnel plots were used to display the relationship between sample size and effect size. If there is no publication bias, the diagram is expected to maintain symmetry (Egger et al. 1997). Second, Kendall's Tau was calculated to evaluate the relationship between effect size and sample size. Finally, Rosenthal's fail-safe number was calculated, which provides a number that indicates how many nonsignificant hypothesis tests would be needed to raise the overall $p$ value to greater than .05 . The robustness of Rosenthal's fail-safe $N$ was evaluated by comparing it against the $5 \mathrm{~N}+10$ threshold (Rosenberg 2005). When the fail-safe $N$ exceeded that threshold, the cumulative effect size is classified as robust.

The current manuscript met the Preferred Reporting Items for Systematic Review and Meta-Analyses (PRISMA) guidelines (Moher et al. 2009). See Supplementary Materials for complete PRISMA checklist. Risk of bias was assessed across studies using the previously stated tests of publication bias and heterogeneity. All included studies were evaluated using the revised Jadad criteria to assess risk of bias within studies (Jadad et al. 1996; Piet and Hougaard 2011). Two raters independently assigned one point for each fulfilled criterion. Each study was assigned a total score which ranged from 0 to 4 (see Table 1). Disagreements between raters were resolved by discussion. Additional sub-analyses were conducted to examine possible effects of risk of bias and study quality.

\section{Results}

\section{Methodological Characteristics of Studies}

See Tables 2, 3, and 4 for detailed information on samples included for each meta-analysis. Fifteen samples (52\%) included health care professionals, while the remaining fourteen $(48 \%)$ included professional health care students, with nurses as the most common primary population $(k=7,24 \%)$. Seventeen samples (59\%) included medical professionals and eleven (38\%) included professionals in a psychological or social field. There were eleven (38\%) samples that investigated manualized treatment protocols, while the remaining 18 $(62 \%)$ utilized an adapted, modified, or abbreviated intervention. Most of the samples $(k=13,45 \%)$ implemented either MBSR $(k=5,17 \%)$ or an adapted version of MBSR $(k=8$, $28 \%$ ). Other types of mindfulness-based interventions were MBCT, ACT, compassion-focused therapy, yoga, and other mindfulness- and compassion-based specialized trainings and programs (see Table 2).

A majority of the samples provided in-person, group-based interventions $(k=25,86 \%)$, with two online-based interventions (7\%), and two interventions that utilized both in-person and online format (7\%). Five samples (17\%) indicated that the intervention was part of an academic class, course, or curriculum. Out of the in-person, group-based interventions, 22 (76\%) samples described the qualifications of the intervention leader or facilitator. Of those samples that reported information on the intervention leader, eight (36\%) explicitly stated that sessions were led by a licensed mental health professional, ten $(45 \%)$ by an experienced or trained individual, three (14\%) were listed as faculty, and one (5\%) was described as a registered yoga teacher. Twelve samples were conducted in the USA (41\%), five in Australia (17\%), four in the UK (14\%), four in Canada (14\%), and the following had one sample each: India (3\%), Portugal (3\%), Brazil (3\%), and the Netherlands (3\%). A strong majority of samples $(k=26$, $90 \%$ ) were peer-reviewed journal articles, and the remaining were dissertations $(k=3,10 \%)$.

The average number of sessions was 7.6, ranging from 1 to 40 sessions. The average duration of a session was 1.82 hour, ranging from 1 to $2.5 \mathrm{~h}$. The average span of an intervention was 6.61 weeks, ranging from 1 to 12 weeks. The average total intervention time (not including home practice) was 


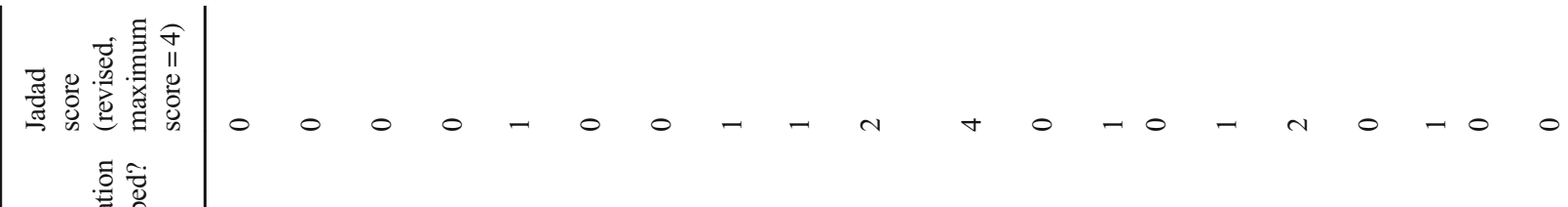

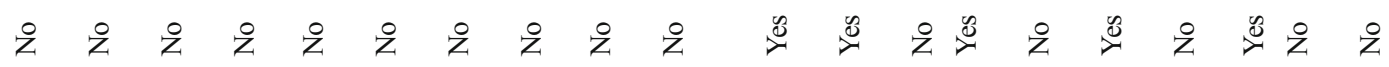

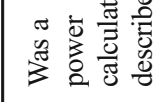

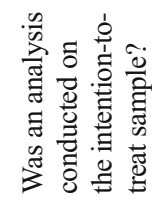

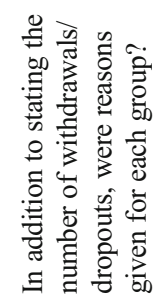
ż

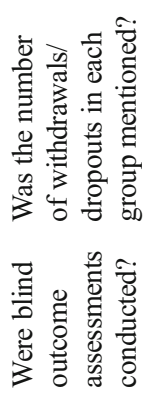

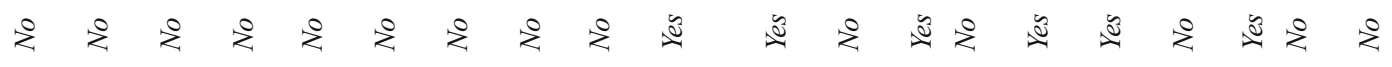

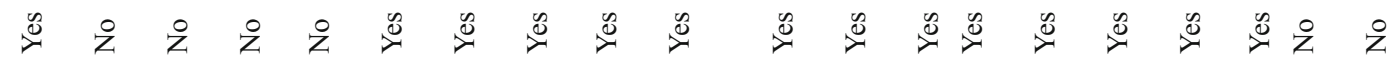

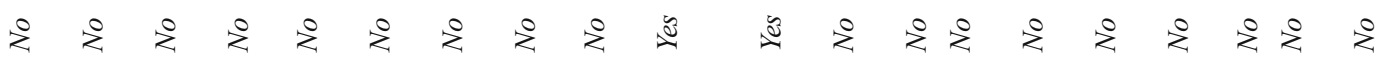

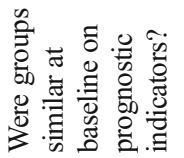

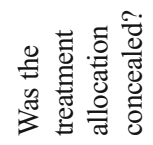
z $\dot{z}$ z

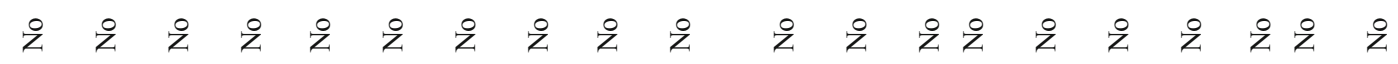

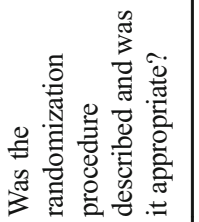

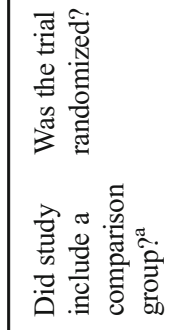

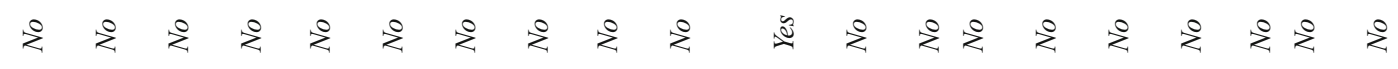

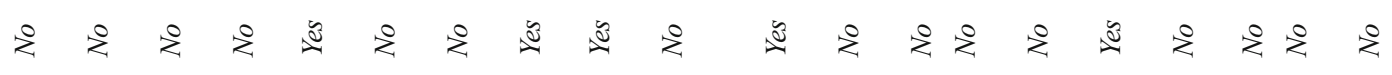

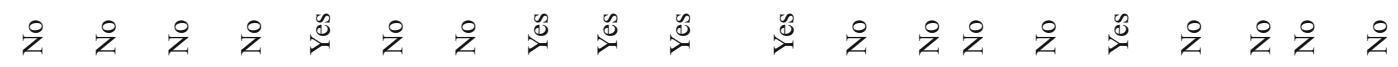

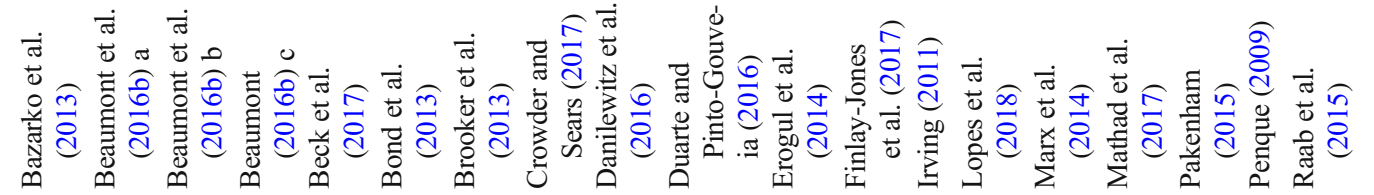




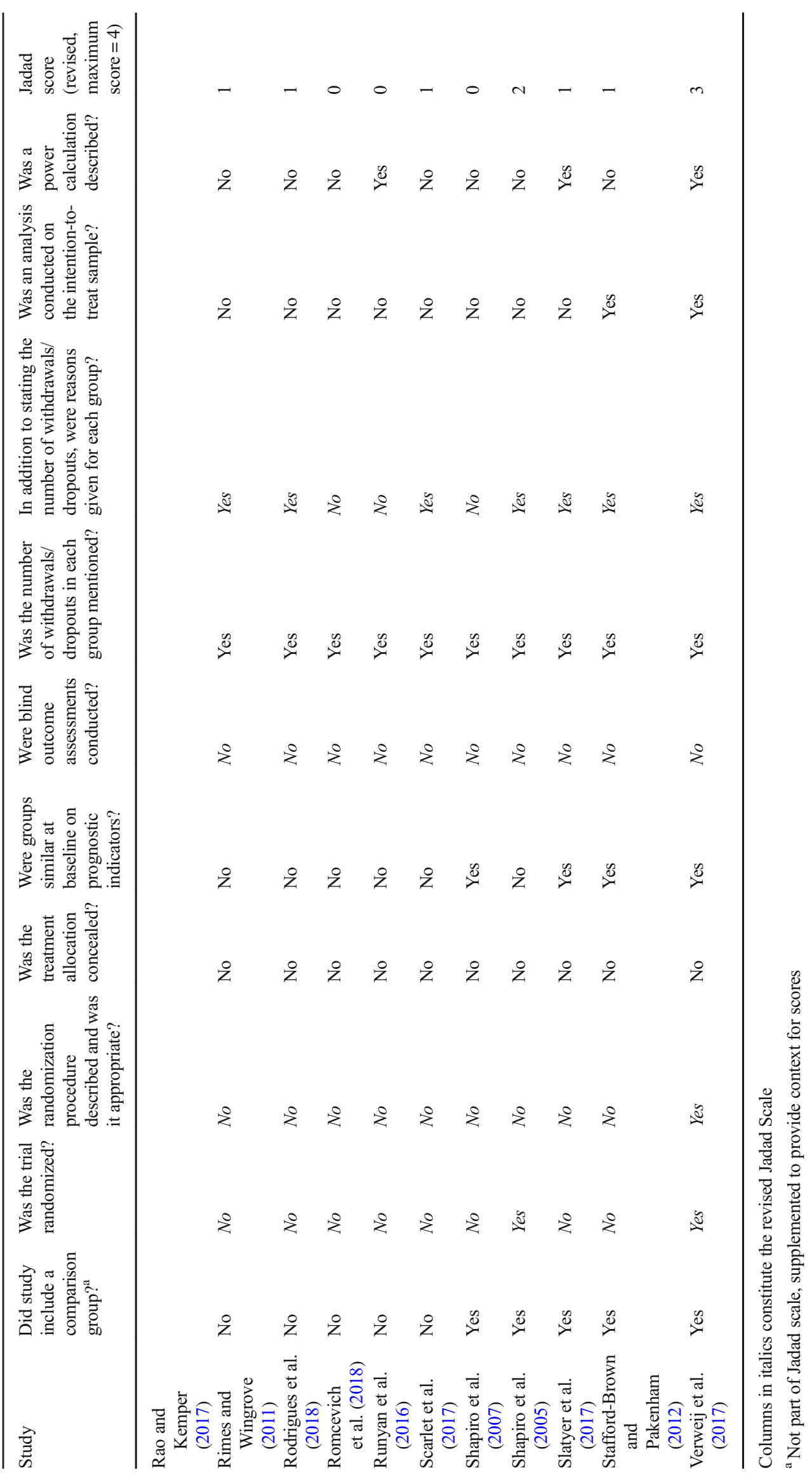




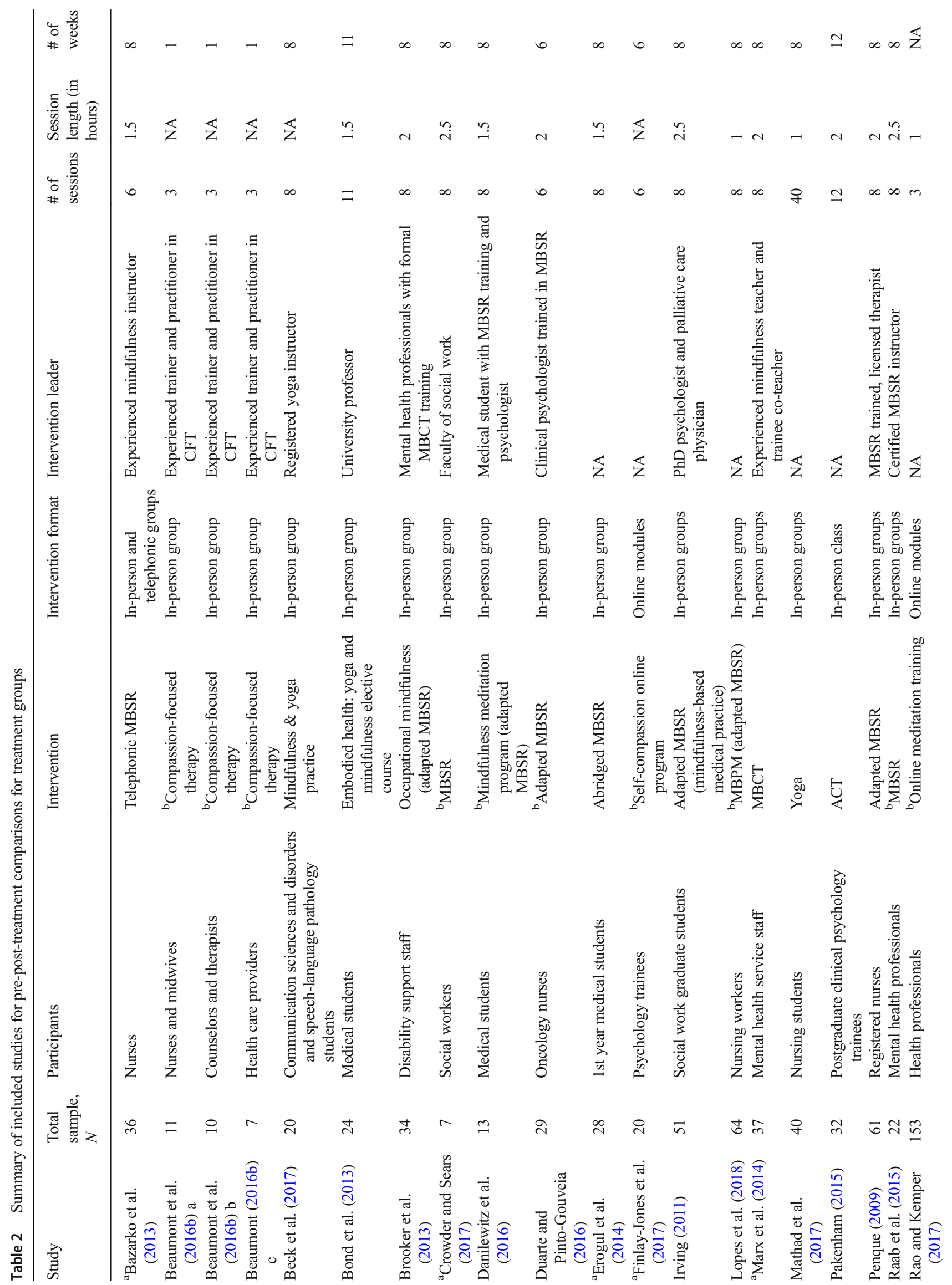




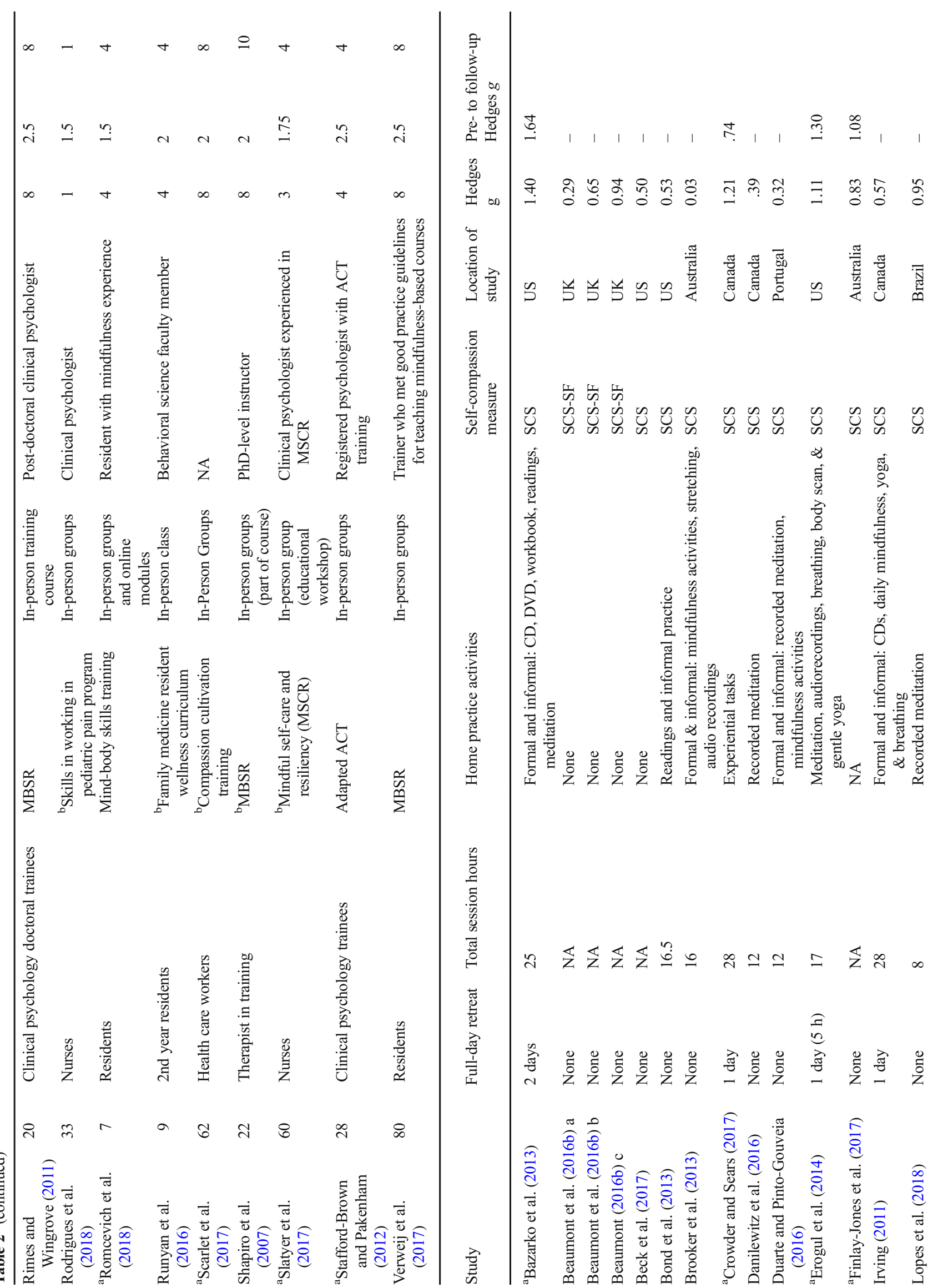




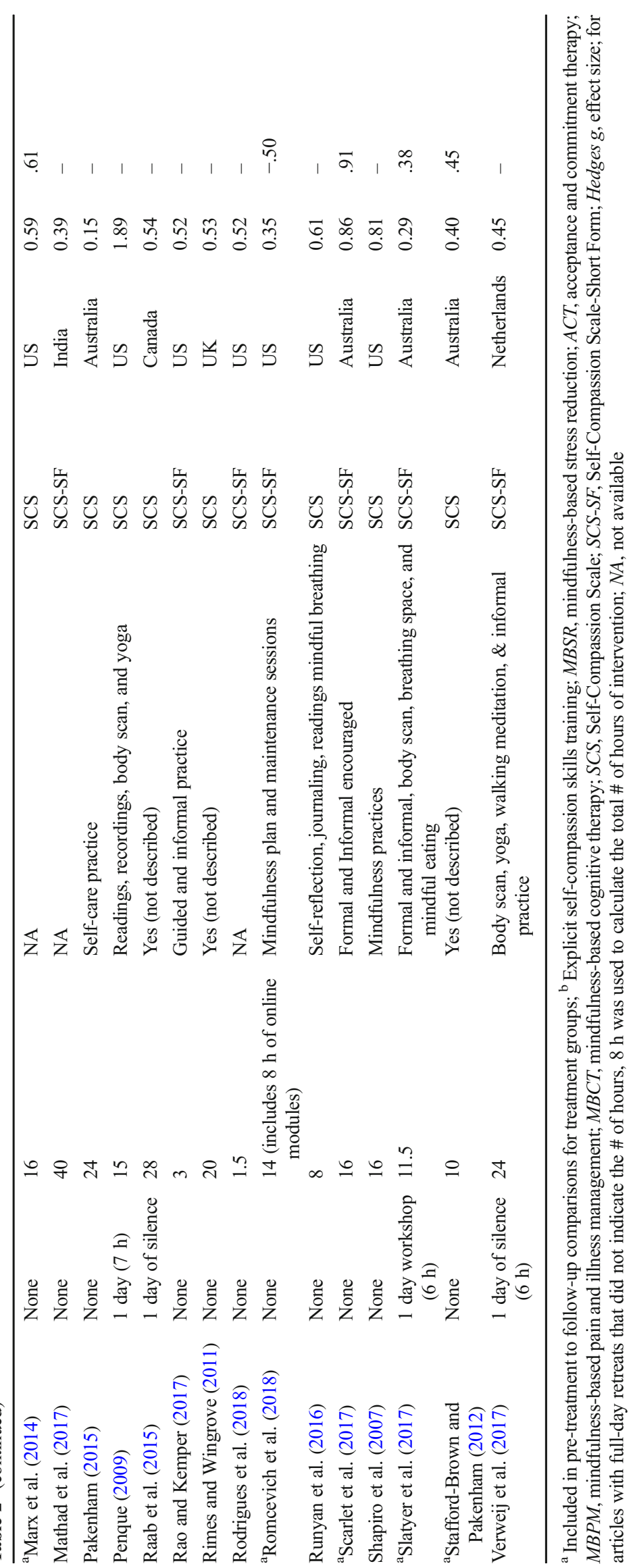


Table 3 Summary of included studies for pre-post-control comparisons for control groups

\begin{tabular}{|c|c|c|c|c|c|c|c|}
\hline Study & $N$ & Participants & $\begin{array}{l}\text { Control } \\
\text { format }\end{array}$ & $\begin{array}{l}\text { \# of } \\
\text { weeks }\end{array}$ & $\begin{array}{l}\text { Location of } \\
\text { study }\end{array}$ & Article type & $\begin{array}{l}\text { Hedges } \\
g\end{array}$ \\
\hline Beck et al. (2017) & 17 & $\begin{array}{l}\text { Communication sciences and disorders and } \\
\text { speech-language pathology students }\end{array}$ & Inactive & 8 & U.S. & Journal & -.21 \\
\hline Crowder and Sears (2017) & 6 & Social workers & Wait-list & 8 & Canada & Dissertation & .54 \\
\hline Danilewitz et al. (2016) & 9 & Medical students & Wait-list & 8 & Canada & Journal & .24 \\
\hline $\begin{array}{l}\text { Duarte and Pinto-Gouveia } \\
\text { (2016) }\end{array}$ & 19 & Oncology nurses & Wait-list & 6 & Portugal & Journal & -.14 \\
\hline Erogul et al. (2014) & 29 & $1^{\text {st }}$ year medical students & Inactive & 8 & U.S. & Journal & .15 \\
\hline Mathad et al. (2017) & 40 & Nursing students & Wait-list & 8 & India & Journal & -.10 \\
\hline Shapiro et al. (2007) & 32 & Therapist in training & Inactive & 10 & U.S. & Journal & -.05 \\
\hline Slatyer et al. (2017) & 19 & Nurses & Wait-list & 4 & Australia & Journal & .00 \\
\hline $\begin{array}{l}\text { Stafford-Brown and } \\
\text { Pakenham (2012) }\end{array}$ & 28 & Clinical psychology trainees & Wait-list & 4 & Australia & Journal & .32 \\
\hline Verweij et al. (2017) & 67 & Residents & Wait-list & 8 & Netherlands & Journal & .17 \\
\hline
\end{tabular}

SCS, Self-Compassion Scale; Hedges g, effect size

$17.06 \mathrm{~h}$, ranging from 1.5 to $40 \mathrm{~h}$. Twenty (69\%) samples had interventions that included 10 or more hours of intervention. Twenty-two $(76 \%)$ samples indicated that their intervention included home practice; however, only sixteen (73\%) studies described the home practice activities. Eight (28\%) samples included at least a 1-day retreat as part of the intervention;

Table 4 Summary of included studies for post-treatment versus post-control comparisons

\begin{tabular}{|c|c|c|c|c|c|c|c|c|c|}
\hline Study & $N$ & $\begin{array}{l}\text { Tx } \\
n\end{array}$ & $\begin{array}{l}\mathrm{Cx} \\
n\end{array}$ & Participants & Intervention & $\begin{array}{l}\text { Self- } \\
\text { compassion } \\
\text { measure }\end{array}$ & Randomized? & $\begin{array}{l}\text { Location of } \\
\text { study }\end{array}$ & $\begin{array}{l}\text { Hedges } \\
g\end{array}$ \\
\hline $\begin{array}{l}\text { Beck et al. } \\
\text { (2017) }\end{array}$ & 37 & 20 & 17 & $\begin{array}{l}\text { Communication sciences and } \\
\text { disorders and speech-language } \\
\text { pathology students }\end{array}$ & $\begin{array}{l}\text { Mindfulness } \\
\text { practice }\end{array}$ & SCS & Non-randomized & US & 0.40 \\
\hline $\begin{array}{l}\text { Crowder and } \\
\text { Sears (2017) }\end{array}$ & 14 & 7 & 7 & Social workers & MBSR & SCS & Randomized & Canada & 0.98 \\
\hline $\begin{array}{l}\text { Danilewitz et al. } \\
\text { (2016) }\end{array}$ & 22 & 13 & 9 & Medical students & $\begin{array}{l}\text { Mindfulness } \\
\text { meditation } \\
\text { program } \\
\text { (adapted MBSR) }\end{array}$ & SCS & Randomized & Canada & 0.35 \\
\hline $\begin{array}{l}\text { Duarte and } \\
\text { Pinto-Gouveia } \\
\text { (2016) }\end{array}$ & 48 & 29 & 19 & Oncology nurses & $\begin{array}{c}\text { Abbreviated } \\
\text { MBSR }\end{array}$ & SCS & Non-randomized & Portugal & 0.03 \\
\hline $\begin{array}{c}\text { Erogul et al. } \\
\text { (2014) }\end{array}$ & 57 & 28 & 29 & Medical students & MBSR & SCS & Randomized & US & 0.88 \\
\hline $\begin{array}{l}\text { Mathad et al. } \\
\text { (2017) }\end{array}$ & 80 & 40 & 40 & Yoga & In-person groups & SCS-SF & Randomized & India & 0.03 \\
\hline $\begin{array}{l}\text { Shapiro et al. } \\
\text { (2007) }\end{array}$ & 54 & 22 & 32 & Trainee therapists & MBSR & SCS & Non-randomized & US & 0.42 \\
\hline $\begin{array}{l}\text { Shapiro et al. } \\
\text { (2005) }\end{array}$ & 38 & 18 & 20 & Health care professionals & MBSR & SCS & Randomized & US & 1.20 \\
\hline $\begin{array}{c}\text { Slatyer et al. } \\
\text { (2017) }\end{array}$ & 76 & 60 & 16 & Nurses & $\begin{array}{l}\text { Mindful self-care } \\
\text { and resiliency } \\
\text { (MSCR) }\end{array}$ & SCS-SF & Non-randomized & Australia & 0.20 \\
\hline $\begin{array}{l}\text { Stafford-Brown } \\
\text { and Pakenham } \\
\text { (2012) }\end{array}$ & 56 & 28 & 28 & Psychology interns & $\begin{array}{l}\text { ACT stress } \\
\text { management }\end{array}$ & SCS & Non-randomized & Australia & 0.61 \\
\hline $\begin{array}{l}\text { Verweij et al. } \\
\text { (2017) }\end{array}$ & 138 & 71 & 67 & Residents & MBSR & SCS-SF & Randomized & Netherlands & 0.38 \\
\hline
\end{tabular}

$N$, total sample size; $n$, sample size; $T x$, treatment group; $C x$, control group; $M B S R$, mindfulness-based stress reduction; $A C T$, acceptance and commitment therapy; SCS, Self-Compassion Scale; $S C S-S F$, Self-Compassion Scale-Short Form; Hedges g, effect size 
however, most did not indicate if the "day of silence" was together with the group or completed individually.

The methodological quality of the included studies using the revised Jadad criteria was reported in Table 1. Across all studies, scores ranged from 0 to 4 points $(M=.80, \mathrm{SD}=1.00)$. When limited to only those studies with a comparison group, scores ranged from 0 to 4 points $(M=1.64, \mathrm{SD}=1.12)$.

\section{Pre-Post-treatment Comparisons Among Treatment Groups}

After all inclusion and exclusion criteria were confirmed, the final number of articles included in the within group pre-posttreatment meta-analysis was $27(k=29, N=1020)$. Table 2 provides a summary of the included studies. The overall effect size was moderate (Hedges $g=.61,95 \% \mathrm{CI}=.47$ to .76 ; see Table 5). The confidence interval did not contain zero; therefore, the null hypothesis of no treatment effect was rejected. The Qtotal was nonsignificant (Qtotal $(28)=30.03, p=.36$ ). The $I^{2}$ of $6.67 \%$ also indicated that there was minimal effect size variation. Figure 2 displays forest plots of effect sizes and confidence intervals. Visual inspection of the funnel plot indicated symmetry suggesting little evidence of publication bias (see Fig. 3). Kendall's Tau was not significant (Tau $=.22, p=.10$ ) which further indicates an absence of publication bias. Rosenthal's fail-safe test suggested that there would have to be at least 790 unpublished, nonsignificant comparisons to raise the overall $p$ value to greater than .05 , which is considered robust.

\section{Pre-treatment to Follow-up Comparisons Among Treatment Groups}

The final number of samples included in this within group meta-analysis was $9(k=9, N=285)$. Articles in Table 2 marked with an "a" were included in the pre-treatment to follow-up comparison. The average follow-up time period was about 15 weeks, ranging from 4 to 24 weeks after the conclusion of the intervention. All samples included only one follow-up time point.

The cumulative effect size was large (Hedges $g=.76,95 \%$ $\mathrm{CI}=.41$ to 1.12 ; see Table 5). The confidence interval did not contain zero; therefore, the null hypothesis of no treatment effect was rejected. The Qtotal was nonsignificant (Qtotal $(8)=11.16, p=.19)$. The $I^{2}$ of $28.32 \%$ indicated that there was a minimal effect size variation. Figure 4 displays forest plots of individual effect sizes and confidence intervals. Visual inspection of the funnel plot indicated symmetry which suggests publication bias was not present (see Fig. 5). Kendall's Tau was not significant (Tau $=.00, p=1.00$ ). Results from Rosenthal's fail-safe test suggested that there would have to be at least 70 unpublished, nonsignificant comparisons to raise the overall $p$ value to greater than .05 , which is considered robust.

\section{Pre-Post-control Comparisons for Control Groups}

The final number of samples included in the within group prepost-control meta-analysis was $10(k=10, N=266)$. Table 3 provides a summary of included samples. Five $(50 \%)$ of the samples were randomized. None of the control groups included an active control treatment. Seven (70\%) samples included a wait-list control group, while the remaining three (30\%) were inactive (or classes as usual).

A cumulative very small and nonsignificant effect size was observed (Hedges $g=.04,95 \% \mathrm{CI}=-.11$ to .20). The confidence interval contained zero; therefore, the null hypothesis cannot be rejected. The Qtotal was nonsignificant (Qtotal $(10)=5.59, p=.78$ ). The $I^{2}$ of 0 indicated there was minimal effect size variation. Figure 6 displays forest plots of included samples. Visual inspection of the funnel plot indicated demonstrated symmetry which suggests an absence of publication bias (see Fig. 7). Kendall's Tau was not significant $($ Tau $=.16, p=.51)$. Rosenthal's fail-safe did not need to be calculated because the overall effect size was already nonsignificant.

Table 5 Random-effects model meta-analyses summary of results

\begin{tabular}{lllllllll}
\hline & $N$ & $k$ & Hedges $g$ & $95 \%$ CI [lower, upper] & QTotal & $I^{2}(\%)$ & Rosenthal's fail-safe & Robust fail-safe cutoff \\
\hline Pre-post-treatment groups & 1020 & 29 & .61 & {$[.47, .76]$} & 30.03 & 6.76 & 790 & 155 \\
Pre-post-treatment groups & 311 & 5 & .58 & {$[.29, .87]$} & 7.23 & 44.67 & 60 & 35 \\
Randomized trials sub-analysis & & & & & & & \\
Pre-post-control groups & 266 & 10 & .04 & {$[-.11, .20]$} & 5.59 & 0.00 & - & - \\
Pre- to follow-up treatment groups & 261 & 9 & .76 & {$[.41,1.12]$} & 11.16 & 28.32 & 70 & 55 \\
Post-treatment versus post-control & 620 & 11 & .48 & {$[.27, .69]$} & 10.84 & 0.00 & 145 & 65 \\
Post-treatment versus post-control & 349 & 6 & .58 & {$[.19, .97]$} & 11.44 & 56.29 & 42 & 40 \\
Randomized trials sub-analysis & & & & & & & & \\
\hline
\end{tabular}

Robust fail-safe cutoff formula: $5(k)+10 ; k$, number of effect sizes 
Fig. 2 Forest plot of Hedges $g$ for pre-post-treatment samples

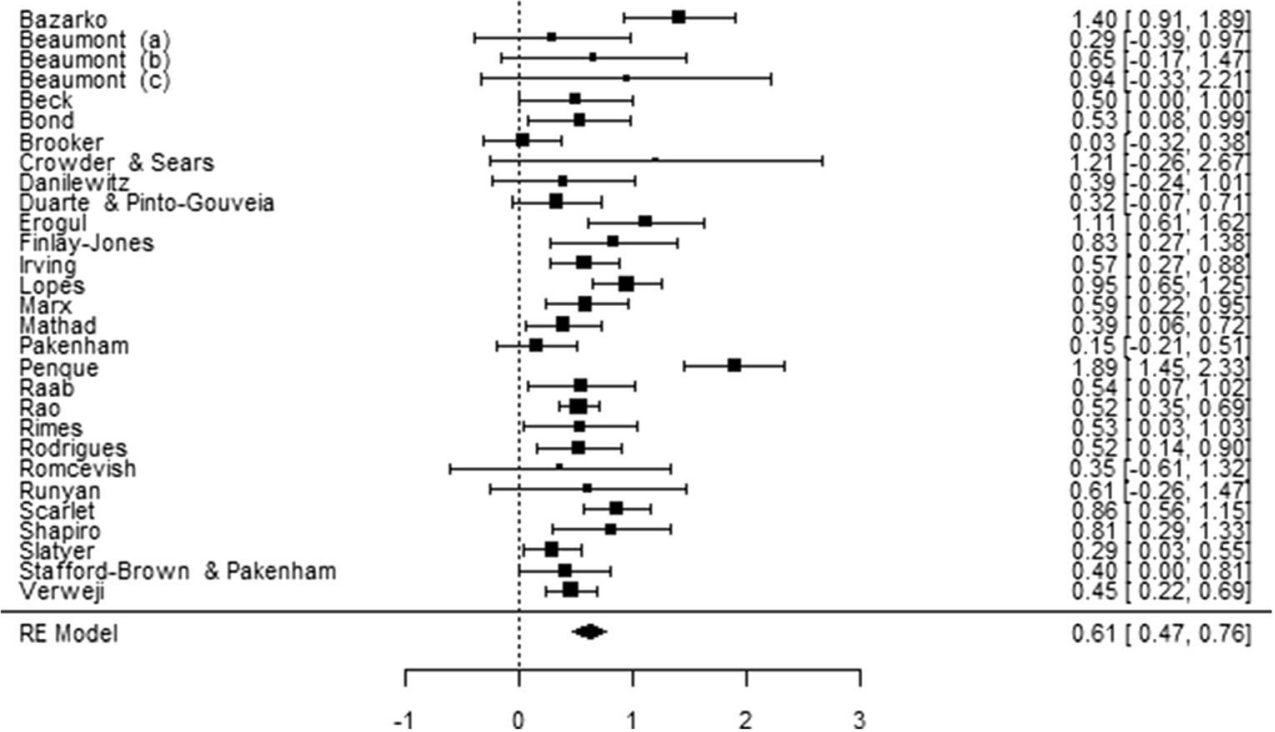

Another way to evaluate the differences between the pre-treatment to post-treatment effect sizes for the treatment and control groups is to calculate the average difference between the two effect sizes (Becker 1988). Ten studies yielded pre-post-effect sizes for both the treatment groups and control groups. The average difference (i.e., $\sum$ (Hedges $d_{\mathrm{rm}}$ for treatment groups - Hedges $d_{\mathrm{rm}}$ for control groups) $/ k$ ) was $.50, \mathrm{SD}=30$. This indicated that the pre-treatment to post-treatment intervention effect size remained moderate after controlling for time effects (Morris and DeShon 2002). These differences were also examined using a paired $t$ test which indicated that the average pre-post-effect size for the treatment group (Hedges $g=.64$ ) was significantly larger than the average pre-post-effect size for the control group (Hedges $g=.09 ; t_{\text {paired }}(9)=5.33, p=.001$ ).

\section{Comparisons Between Post-treatment and Post-control Groups}

After all inclusion and exclusion criteria were verified, the final number of samples included in the between groups post-treatment versus post-control meta-analysis was $11(k=$ $11, N=620$ ). See Table 4 for a summary of the included samples.

There was a moderate cumulative effect size comparing treatment group versus control group self-compassion scores at post-intervention (Hedges $g=.48,95 \% \mathrm{CI}=.27$ to .69; see Table 5). The confidence interval did not contain zero; therefore, the null hypothesis of no treatment effect was rejected. The Qtotal was nonsignificant (Qtotal $(11)=10.84, p=.46)$. The $I^{2}$ of $0 \%$ indicated that there was a very little effect size variation. Figure 8 displays a forest plot of individual effect sizes and confidence

Fig. 3 Funnel plot to assess publication bias for pre-post-treatment samples 
Fig. 4 Forest plot of Hedges $g$ for pre-treatment to follow-up samples

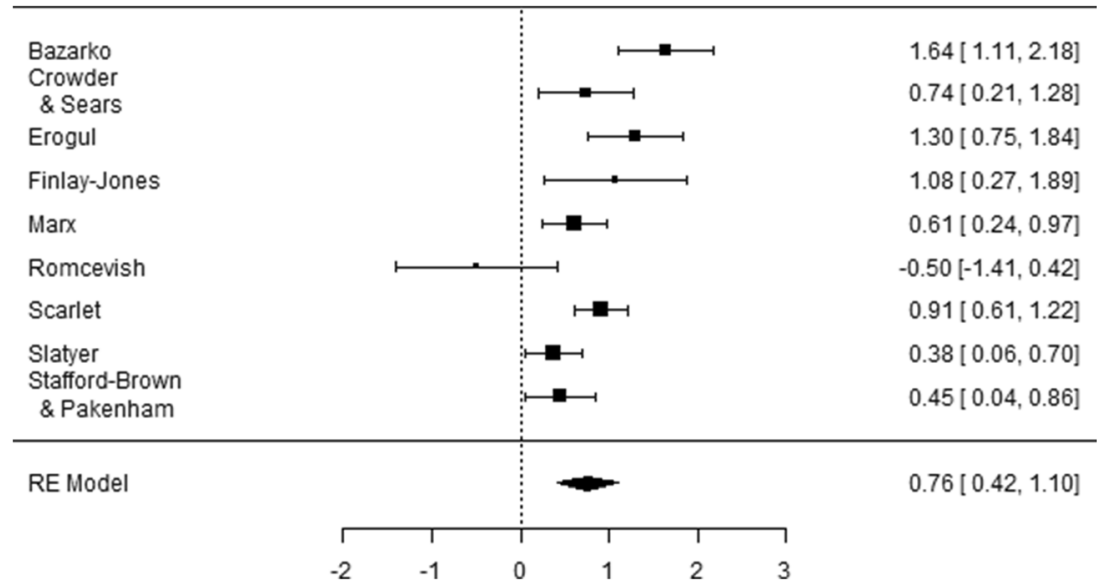

intervals. Visual inspection of the funnel plot indicated symmetry suggesting that there is little evidence of publication bias (see Fig. 9). Kendall's Tau was not significant (Tau $=.03, p=.89$ ). Results from Rosenthal's failsafe suggested that there would have to be at least 145 unpublished, nonsignificant comparisons to raise the overall $p$ value to greater than .05 , which is considered robust.

\section{Moderator Analyses}

All primary analyses indicated that there was no significant heterogeneity in effect sizes (Table 5). However, for exploratory purposes, several possible moderators were conducted for pre-post-treatment overall effect size for the treatment groups. These moderators included participant characteristics (e.g., students vs. professionals; medical field vs. psychological field), intervention characteristics (e.g., manualized interventions vs. modified interventions; 12 or less total interventions hours vs. more 12 total intervention hours), and risk of bias. One moderator was identified as significant, indicating that studies with a retreat had a significantly larger effect size than those without a retreat. No other moderator analyses

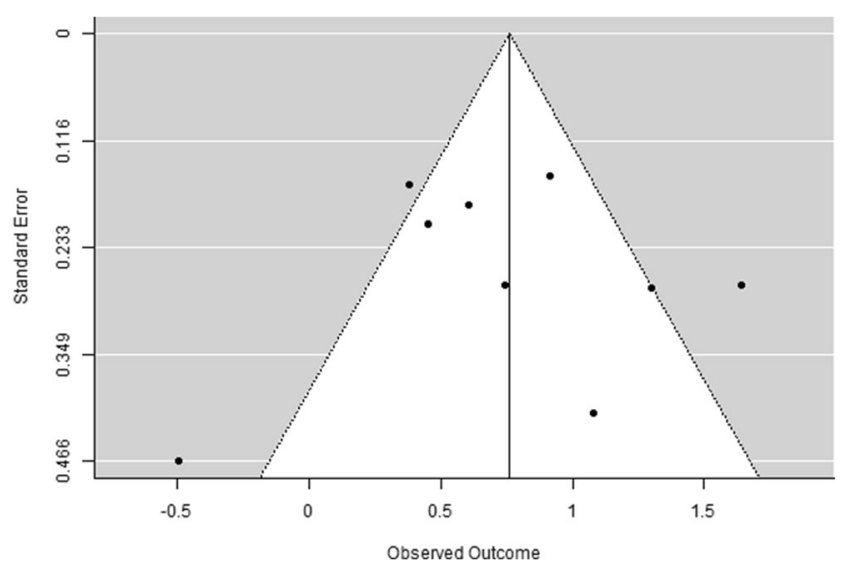

Fig. 5 Funnel plot to assess publication bias for pre-treatment to followup samples indicated that other methodological variations were associated with different levels of intervention effects (see Table 6). A moderator analysis was also conducted to investigate the effects of randomization for the post-treatment versus postcontrol comparison and was nonsignificant.

\section{Discussion}

This meta-analysis evaluated the effects of mindfulness-based interventions on self-compassion among health care professionals. An intermediate and reliable effect size was observed for pre-post-differences among treatment groups as well as treatment group versus control group comparisons at posttreatment. A large effect size was observed for pre-treatment to follow-up differences among treatment groups. The prepost effect size for control groups was small, nonsignificant, and significantly smaller than the pre-post-difference for treatment groups. There was no evidence of publication bias among effect sizes; however, there is possible risk of bias within most of the studies. Studies with retreats included as part of intervention demonstrated a significantly larger effect size than those without retreats. No other significant moderators were identified. Finally, Rosenthal's fail-safe values indicated that a large number of nonsignificant comparisons from unpublished studies would need to be stored in researchers' file drawers to disconfirm the meta-analytic findings that mindfulness-based interventions exerted moderate to large and statistically significant improvements in self-compassion.

These findings parallel with meta-analytic results from Kirby et al. (2017) on self-compassion interventions for the general population $(d=.70, k=13,95 \% \mathrm{CI}=.53-.87$, $p<.001)$. Moreover, the current findings suggest that mindfulness-based interventions help improve selfcompassion specifically in health care students and professionals. Importantly, the consistency among effect sizes and lack of moderator effects indicates that a range of intervention formats, leader types, number of sessions, total number of 
Fig. 6 Forest plot of Hedges $g$ for pre-post-control samples

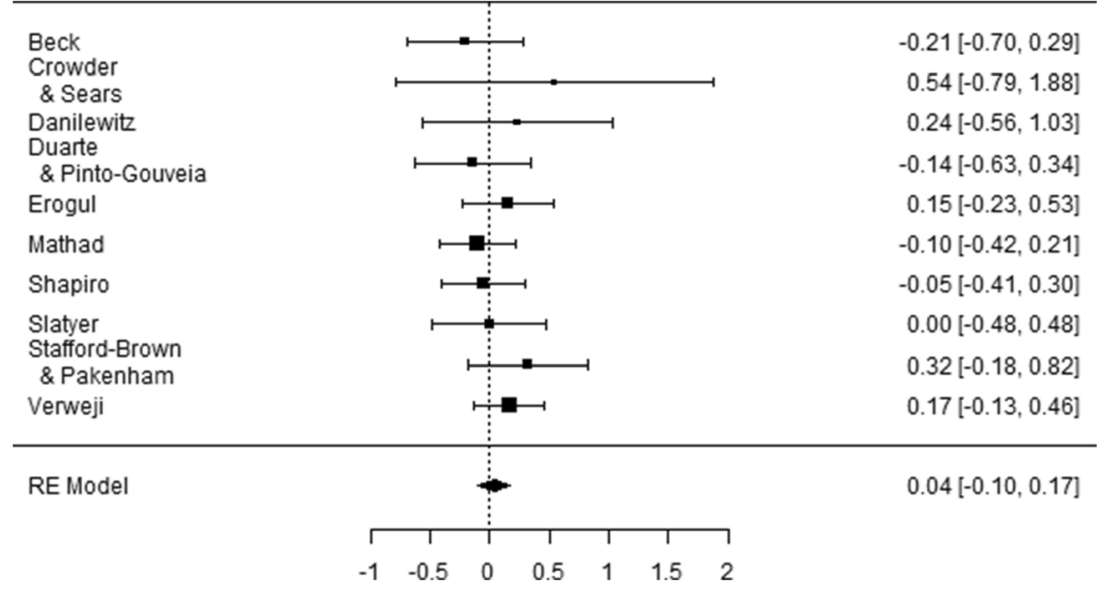

There was a larger effect size for pre-treatment to hours of intervention, and home practice activities yield positive effects on self-compassion. In turn, this information suggests that medical settings and training facilities can have flexibility in the format and implementation of these kinds of programs and interventions for their employees and trainees. The current findings also extend upon Burton et al.'s (2017) interpretation from their meta-analysis that multiple forms of mindfulness-based interventions, not just MBSR, can reduce stress and benefit health care professionals.

The current meta-analytic findings combined with the prior meta-analytic findings suggest that organizations can implement mindfulness-based interventions for health care professionals with an expectation that improvements in self-compassion, stress, depression, and anxiety will be observed (Burton et al. 2017; Dharmawardene et al. 2016). Further, it is reasonable to speculate that improvements in these outcomes may engender better-quality patient care. Finally, some studies suggest that the most significant changes in mindful care occurs when mindfulness training is implemented at an organizational level, generating a compassionate and supportive environment (Barratt 2017; Leonard 2016).

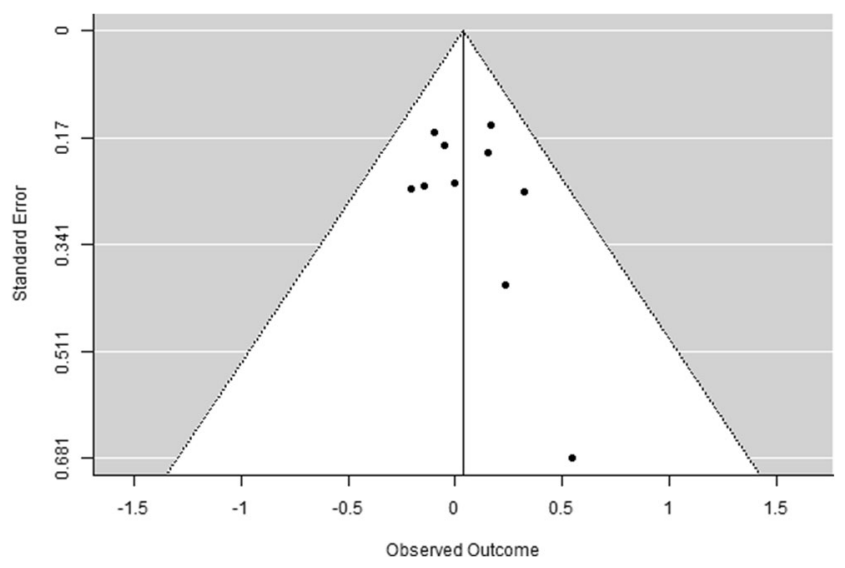

Fig. 7 Funnel plot to assess publication bias for pre-post-control samples follow-up comparisons relative to the pre-post-treatment comparisons. This may suggest that the effects of a mindfulness-based intervention are not only maintained but continue to strengthen over time. This is an important finding that should encourage researchers to collect more long-term outcome data when possible. Of note, most of the samples included in the pre-treatment to follow-up analysis had distributed information and resources to participants to continue their practice, and only one offered an optional "booster" session. If institutions are to invest in a mindfulness-based intervention for their employees or students, it would likely be worthwhile for them to include home resources (e.g., audio recordings, home practice plans, handouts, workbooks) to maintain or further develop the benefits gained from the initial intervention.

In regard to the types of interventions utilized, a majority of the studies implemented a version of MBSR. MBSR was the first manualized psychological treatment that incorporated mindfulness. Even though there have been several popular, empirically supported, manualized treatments that have a strong mindfulness component (e.g., MBCT, ACT, DBT), it appears that training and organizational settings have a preference for MBSR. It is possible that institutions prefer a "stress reduction" program, compared with programs that may seem to be designed to address "problems" or psychopathology. Therefore, MBSR may be more acceptable to health care students and professionals. Additionally, MBSR was designed for a medical setting, which may make it more appropriate for these populations.

Health care professionals have significant time constraints, making it difficult for them to commit to weekly mindfulness-based interventions. The question of the appropriate "dosage" of mindfulness interventions is not a new one (Bartlett et al. 2019; Carmody and Baer 2009). There is some support in the literature to suggest that higher dose mindfulness training produces stronger effects 
Fig. 8 Forest plot of Hedges $g$ for post-treatment vs. post-control samples

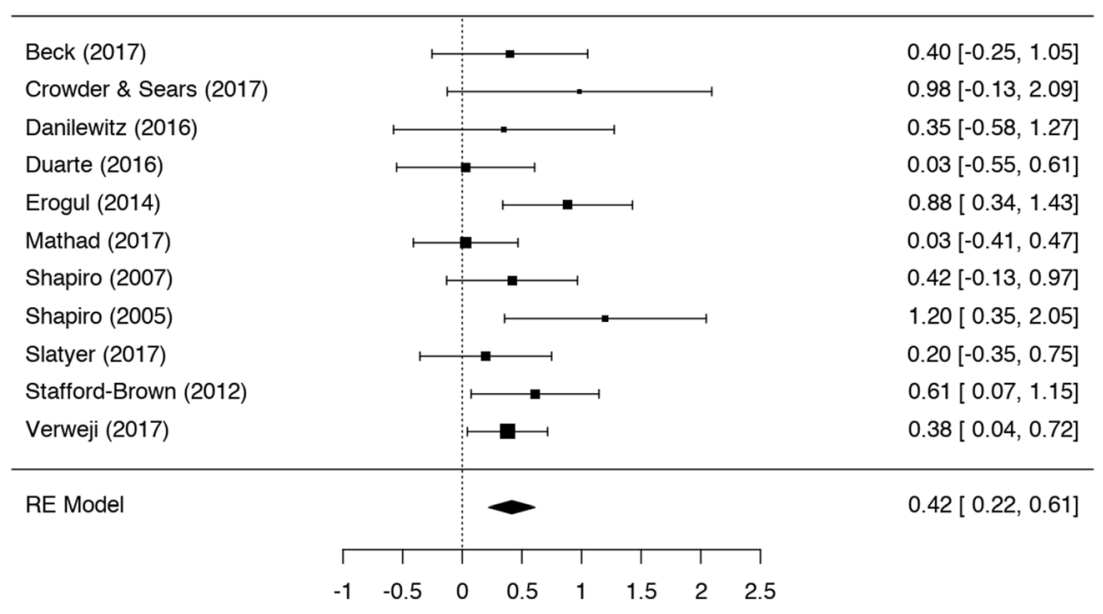

in well-being compared with lower dose training (e.g., single-day training) in a general working population (Chin et al. 2019). The current meta-analysis found that studies that included a retreat component (e.g., day of silence) demonstrated a significantly larger effect size than those without. It may be that the scheduling of a retreat component allowed the participants to experience a higher dose of the mindfulness intervention. At the same time, a retreat element would allow participants to be more disengaged from the everyday stressors and workrelated time constraints. Further exploration of the relative advantages of a retreat element for health care professionals is warranted.

It is noteworthy that the included articles date back only to 2005 . This is likely due to the relatively recent emergence of the valid and reliable measurement selfcompassion (Neff 2003). The timing of the construct overlaps with the recent movement to employ mindfulnessbased interventions for health care professionals. Over the past decade, there has been a growth in the number of studies implementing and evaluating the effects of

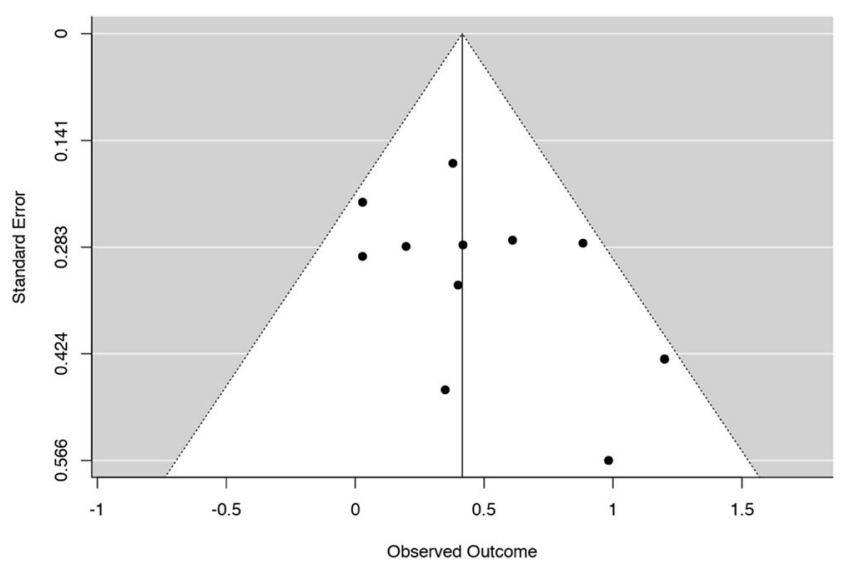

Fig. 9 Funnel plot to assess publication bias for post-treatment vs. postcontrol samples interventions for this population (Regehr et al. 2014; West et al. 2016). Based on the growth in the number of these implemented programs and empirical evidence of their effectiveness, it is likely that researchers in this field will continue to publish similar articles. With this assumption, there are a few recommendations for future research based on the findings and limitations of the current study.

\section{Limitations and Future Research}

First, many studies did not meet inclusion criteria for the current meta-analysis due to insufficient data presented. Future studies should report, at the least, means, standard deviations, sample sizes, and pre-post correlations among dependent variables. Second, as more studies are published on this topic, possible outcome moderators may be identified, as the moderator analyses were likely underpowered (Hedges and Pigott 2001). Third, there may be other unmeasured moderators that can help distinguish aspects of interventions that may be associated with effectiveness and thereby better inform clinical practice (e.g., intervention type, duration, content, home practice). Specifically, it would be important for future researchers to explore differences in outcomes after inventions with explicit versus implicit focus on teaching self-compassion. A fourth limitation was the analysis of only self-report measures. It would be important to have a better understanding of whether change in self-compassion corresponds with change in objective indices of self-care and patient care behaviors. A fifth limitation was the broad scope of our inclusion criteria for types of health care professionals and types of interventions. While our purpose was to evaluate the extent to which mindfulness interventions influenced self-compassion in professional caregivers who are at risk of compassion fatigue and burnout, regardless of their job title and years of work, we may have missed important nuances between interventions and specific 
Table 6 Moderator analyses for pre-post-treatment groups

\begin{tabular}{|c|c|c|c|c|c|}
\hline & $k$ & Hedges $g$ & 95\% CI [lower, upper] & $Z$ & $p$ \\
\hline Students & 14 & .50 & {$[.39, .61]$} & 1.00 & .32 \\
\hline Professionals & 15 & .70 & {$[.49, .96]$} & & \\
\hline Manualized protocol & 11 & .56 & {$[.39, .72]$} & 0.41 & .68 \\
\hline Modified protocol & 18 & .64 & {$[.43, .85]$} & & \\
\hline Medical field HCP & $15^{\mathrm{a}}$ & .68 & {$[.43, .92]$} & 0.65 & .51 \\
\hline Psychological/social field HCP & 10 & .53 & {$[.38, .67]$} & & \\
\hline$\leq 12 \mathrm{~h}$ total intervention time & 6 & .54 & {$[.33, .75]$} & 0.52 & .60 \\
\hline$>12 \mathrm{~h}$ total intervention time & 18 & .65 & {$[.43, .87]$} & & \\
\hline Home practice & 21 & .64 & {$[.45, .83]$} & 0.73 & .64 \\
\hline No home practice & 8 & .53 & {$[.36, .69]$} & & \\
\hline Explicit self-compassion (at minimum, loving-kindness meditation) & 16 & .44 & {$[.44, .72]$} & 0.33 & .75 \\
\hline Implicit self-compassion & 13 & .65 & {$[.37, .93]$} & & \\
\hline Retreat & 8 & .89 & {$[.48,1.30]$} & 2.04 & $.04 *$ \\
\hline No retreat & 21 & .52 & {$[.39, .64]$} & & \\
\hline In-person & 25 & .59 & {$[.43, .74]$} & 0.58 & .56 \\
\hline Part or full online ${ }^{\mathrm{b}}$ & 4 & .80 & {$[.35,1.26]$} & & \\
\hline$\leq 6$ sessions & 12 & .55 & {$[.36, .75]$} & 0.03 & .98 \\
\hline$>6$ sessions & 17 & .65 & {$[.44, .86]$} & & \\
\hline${ }^{\mathrm{c}}$ Randomized & 6 & .58 & {$[.19, .97]$} & 0.87 & .38 \\
\hline${ }^{c}$ Non-randomized & 5 & .34 & {$[.09, .60]$} & & \\
\hline High Jadad quality rating (2-4) & 4 & .52 & {$[.25, .80]$} & 0.43 & .67 \\
\hline Low Jadad quality rating $(0-1)$ & 25 & .63 & {$[.46, .78]$} & & \\
\hline
\end{tabular}

*Significant difference; $k=$ number of effect sizes

${ }^{a}$ Only 25 effect sizes were utilized because 4 had mixed populations

${ }^{b}$ Two studies were all online, while two were a mix of in-person groups with an online supplement

${ }^{\mathrm{c}}$ Moderator analysis conducted for post-treatment versus post-control comparison

types of health care providers. Sixth, results from the study quality ratings indicated that many studies did not use a randomized control trial design and did not sufficiently report their methodological procedures. It is recommended that primary researchers refer to standardized reporting guidelines, such as Jadad et al. (1996), to increase methodological quality. Finally, there is a lack of active control group comparisons which limits the external validity of our findings. Moreover, it makes it difficult to determine whether mindfulness-based techniques per se are promoting improvements in self-compassion over and above nonspecific intervention and group variables such as social support, empathy, and problem-solving. The proposed recommendations parallel previous researchers' conclusions, more studies are warranted to better understand the effects of specific intervention components and "dosage," as well as the need for more rigorous study designs (Burton et al. 2017; Dharmawardene et al. 2016).

This meta-analysis indicated that mindfulness-based interventions can promote improvements in self-compassion among a variety of health care professionals. Previous research has shown that health care professionals experience high rates of stress, burnout, and compassion fatigue, which have been correlated with poorer patient satisfaction and more medical errors. Future studies with rigorous methodological designs evaluating the impact of increased self-compassion via mindfulness-based interventions on objective indictors of self-care, quality of patient care, and job performance would be beneficial. Studies evaluating the differences between key variables, such as interventions with implicit versus explicit compassion skills and levels of training (students vs. employees), are warranted. Additionally, self-compassion as a protective factor for burnout and compassion fatigue in this population should be investigated.

Author's Contributions RW designed and executed the study, completed data analyses, and wrote the paper. CB collaborated with the methodological design and editing of the final manuscript. WO collaborated with the methodological design and assisted with data analyses and writing of the study. All authors approved the final version of the manuscript for submission.

\section{Compliance with Ethical Standards}

Conflict of Interest The authors declare that they have no conflict of interest.

Ethical Approval This article does not contain any studies with human participants or animals performed by any of the authors.

\section{References}

Articles with an asterisk denotes that it was used in the metaanalysis.

Aiken, L. H., Clarke, S. P., Sloane, D. M., Sochalski, J., \& Silber, J. H. (2002). Hospital nurse staffing and patient mortality, nurse burnout, and job dissatisfaction. JAMA, 288(16), 1987-1993. 
Barnard, L. K., \& Curry, J. F. (2011). Self-compassion: Conceptualizations, correlates, \& interventions. Review of General Psychology, 15(4), 289-303.

Barratt, C. (2017). Exploring how mindfulness and self-compassion can enhance compassionate care. Nursing Standard (2014+), $31(21), 55$

Bartlett, L., Martin, A., Neil, A. L., Memish, K., Otahal, P., Kilpatrick, M., \& Sanderson, K. (2019). A systematic review and meta-analysis of workplace mindfulness training randomized controlled trials. Journal of Occupational Health Psychology, 24(1), 108-126.

*Bazarko, D., Cate, R. A., Azocar, F., \& Kreitzer, M. J. (2013). The impact of an innovative mindfulness-based stress reduction program on the health and well-being of nurses employed in a corporate setting. Journal of Workplace Behavioral Health, 28(2), 107-133.

Beaumont, E., Durkin, M., Hollins Martin, C. J., \& Carson, J. (2016a). Measuring relationships between self-compassion, compassion fatigue, burnout and well-being in student counsellors and student cognitive behavioural psychotherapists: A quantitative survey. Counselling and Psychotherapy Research, 16(1), 15-23.

*Beaumont, E., Irons, C., Rayner, G., \& Dagnall, N. (2016b). Does compassion-focused therapy training for health care educators and providers increase self-compassion and reduce self-persecution and self-criticism?. Journal of Continuing Education in the Health Professions, 36(1), 4-10.

*Beck, A. R., Verticchio, H., Seeman, S., Milliken, E., \& Schaab, H. (2017). A mindfulness practice for communication sciences and disorders undergraduate and speech-language pathology graduate students: Effects on stress, self-compassion, and perfectionism. American Journal of Speech-Language Pathology, 26(3), 893-907.

Becker, B. J. (1988). Synthesizing standardized mean change scores. British Journal of Mathematical and Statistical Psychology, 41, 257-278.

Birnie, K., Speca, M., \& Carlson, L. E. (2010). Exploring selfcompassion and empathy in the context of mindfulness-based stress reduction (MBSR). Stress and Health, 26(5), 359-371.

*Bond, A. R., Mason, H. F., Lemaster, C. M., Shaw, S. E., Mullin, C. S., Holick, E. A., \& Saper, R. B. (2013). Embodied health: The effects of a mind-body course for medical students. Medical Education Online, 18(1), 20699.

Brazeua, C., Schroeder, R., Rovi, S., \& Boyd, L. (2010). Relationships between medical student burnout, empathy, and professionalism climate. Academic Medicine, 85, S33-S36.

*Brooker, J., Julian, J., Webber, L., Chan, J., Shawyer, F., \& Meadows, G. (2013). Evaluation of an occupational mindfulness program for staff employed in the disability sector in Australia. Mindfulness, 4(2), 122-136.

Burton, A., Burgess, C., Dean, S., Koutsopoulou, G. Z., \& Hugh-Jones, S. (2017). How effective are mindfulness-based interventions for reducing stress among healthcare professionals? A systematic review and meta-analysis. Stress and Health, 33(1), 3-13.

Byron, G., Ziedonis, D. M., McGrath, C., Frazier, J. A., deTorrijos, F., \& Fulwiler, C. (2015). Implementation of mindfulness training for mental health staff: Organizational context and stakeholder perspectives. Mindfulness, 6(4), 861-872.

Carmody, J., \& Baer, R. A. (2009). How long does a mindfulness-based stress reduction program need to be? A review of class contact hours and effect sizes for psychological distress. Journal of Clinical Psychology, 65(6), 627-638.

Chiappetta, M., D'Egidio, V., Sestili, C., Cocchiara, R. A., \& La Torre, G. (2018). Stress management interventions among healthcare workers using mindfulness: A systematic review. Senses and Sciences, 5(2).

Chin, B., Slutsky, J., Raye, J., \& Creswell, J. D. (2019). Mindfulness training reduces stress at work: A randomized controlled trial. Mindfulness, 10(4), 627-638.

Cocker, F., \& Joss, N. (2016). Compassion fatigue among healthcare, emergency and community service workers: A systematic review.
International Journal of Environmental Research and Public Health, 13(6), 618

"Crowder, R., \& Sears, A. (2017). Building resilience in social workers: An exploratory study on the impacts of a mindfulness-based intervention. Australian Social Work, 70(1), 17-29.

*Danilewitz, M., Bradwejn, J., \& Koszycki, D. (2016). A pilot feasibility study of a peer-led mindfulness program for medical students. Canadian Medical Education Journal, 7(1), e31.

Dharmawardene, M., Givens, J., Wachholtz, A., Makowski, S., \& Tjia, J. (2016). A systematic review and meta-analysis of meditative interventions for informal caregivers and health professionals. $B M J$ Supportive \& Palliative Care, 6(2), 160-169.

"Duarte, J., \& Pinto-Gouveia, J. (2016). Effectiveness of a mindfulnessbased intervention on oncology nurses' burnout and compassion fatigue symptoms: A non-randomized study. International Journal of Nursing Studies, 64, 98-107.

Duarte, J., Pinto-Gouveia, J., \& Cruz, B. (2016). Relationships between nurses' empathy, self compassion and dimensions of professional quality of life: A cross-sectional study. International Journal of Nursing Studies, 60, 1-11.

Dyrbye, L. N., Thomas, M. R., \& Shanafelt, T. D. (2005). Medical student distress: Causes, consequences, and proposed solutions. Mayo Clinic Proceedings, 80(12), 1613-1622 Elsevier.

Egger, M., Smith, G. D., Schneider, M., \& Minder, C. (1997). Bias in meta-analysis detected by a simple, graphical test. British Medical Journal, 315(7109), 629-634.

*Erogul, M., Singer, G., McIntyre, T., \& Stefanov, D. G. (2014). Abridged mindfulness intervention to support wellness in first-year medical students. Teaching and Learning in Medicine, 26(4), 350 356.

*Finlay-Jones, A., Kane, R., \& Rees, C. (2017). Self-compassion online: A pilot study of an internet-based self-compassion cultivation program for psychology trainees. Journal of Clinical Psychology, 73(7), 797-816.

Galantino, M. L., Baime, M., Maguire, M., Szapary, P. O., \& Farrar, J. T. (2005). Association of psychological and physiological measures of stress in health-care professionals during an 8-week mindfulness meditation program: Mindfulness in practice. Stress and Health: Journal of the International Society for the Investigation of Stress, 21(4), 255-261.

Gallagher, R. (2013). Compassion fatigue. Canadian Family Physician, $59(3), 265-268$.

Gilbert, P. (2005). Compassion and cruelty: A biopsychosocial approach. Routledge.

Hedges, L. V. (1982). Estimation of effect size from a series of independent experiments. Psychological Bulletin, 92, 490-499.

Hedges, L. V., \& Pigott, T. D. (2001). The power of statistical tests in meta-analysis. Psychological Methods, 6(3), 203-217.

Higgins, J. P. T., \& Thompson, S. G. (2002). Quantifying heterogeneity in a meta-analysis. Statistics in Medicine, 21, 1539-1558.

Huedo-Medina, T. N., Sanchez-Meca, J., \& Marin-Martinez, F. (2006). Assessing heterogeneity in meta analysis: Q statistic or I2 index? Psychological Methods, 2, 193-206.

*Irving, J. A. (2011). Mindfulness-based medical practice: A mixedmethods investigation of an adapted mindfulness-based stress reduction program for health care professionals. (Unpublished doctoral dissertation). McGill University, Montreal.

Irving, J. A., Dobkin, P. L., \& Park, J. (2009). Cultivating mindfulness in health care professionals: A review of empirical studies of mindfulness-based stress reduction (MBSR). Complementary Therapies in Clinical Practice, 15(2), 61-66.

Jadad, A. R., Moore, R. A., Carroll, D., Jenkinson, C., Reynolds, D. J. M., Gavaghan, D. J., \& McQuay, H. J. (1996). Assessing the quality of reports of randomized clinical trials: Is blinding necessary? Controlled Clinical Trials, 17(1), 1-12. 
Kabat-Zinn, J. (1994). Wherever you go, there you are: Mindfulness meditation in everyday life (p. 4). New York: Hyperion.

Kemper, K. J., Mo, X., \& Khayat, R. (2015). Are mindfulness and selfcompassion associated with sleep and resilience in health professionals? The Journal of Alternative and Complementary Medicine, 21(8), 496-503.

Khoury, B., Lecomte, T., Fortin, G., Masse, M., Therien, P., Bouchard, V., et al. (2013). Mindfulness-based therapy: A comprehensive metaanalysis. Clinical Psychology Review, 33(6), 763-771.

Kirby, J. N., Tellegen, C. L., \& Steindl, S. R. (2017). A meta-analysis of compassion-based interventions: Current state of knowledge and future directions. Behavior Therapy, 48(6), 778-792.

Klimecki, O., \& Singer, T. (2012). Empathic distress fatigue rather than compassion fatigue? Integrating findings from empathy research in psychology and social neuroscience. Pathological altruism, 368383.

Leary, M. R., Tate, E. B., Adams, C. E., Batts Allen, A., \& Hancock, J. (2007). Self-compassion and reactions to unpleasant self-relevant events: The implications of treating oneself kindly. Journal of Personality and Social Psychology, 92(5), 887-904.

Lee, F., Brown, J., \& Stewart, M. (2009). Exploring family physician stress: Helpful strategies. Canadian Family Physician, 55(3), 288 289

Leiter, M. P., Harvie, P., \& Frizzell, C. (1998). The correspondence of patient satisfaction and nurse burnout. Social Science \& Medicine, 47(10), 1611-1617.

Leonard, M. (2016). Making mindfulness meditation accessible and meaningful. In M. Chapman-Clarke (Ed.), Mindfulness in the workplace: An evidence-based approach to improving wellbeing and maximizing performance (pp. 245-264). London: Kogan Page Publishers.

*Lopes, S. A., Vannucchi, B. P., Demarzo, M., Cunha, Â. G. J., \& Nunes, M. D. P. T. (2018). Effectiveness of a mindfulness-based intervention in the management of musculoskeletal pain in nursing workers. Pain Management Nursing, 20(20), 32-38.

Luberto, C. M., Wasson, R. S., Kraemer, K. M., Sears, R. W., Hueber, C., \& Cotton, S. (2017). Feasibility, acceptability, and preliminary effectiveness of a 4-week mindfulness-based cognitive therapy protocol for hospital employees. Mindfulness, 8(6), 1522-1531.

MacBeth, A., \& Gumley, A. (2012). Exploring compassion: A metaanalysis of the association between self-compassion and psychopathology. Clinical Psychology Review, 32(6), 545-552.

*Mahon, M. A., Mee, L., Brett, D., \& Dowling, M. (2017). Nurses' perceived stress and compassion following a mindfulness meditation and self compassion training. Journal of Research in Nursing, 22(8), 572-583.

*Marx, R., Strauss, C., \& Williamson, C. (2014). The eye of the storm: A feasibility study of an adapted mindfulness-based cognitive therapy (MBCT) group intervention to manage NHS staff stress. The Cognitive Behaviour Therapist, 7, e18.

Maslach, C., Jackson, S., \& Leiter, M. (1996). Maslach burnout inventory manual (3rd ed.). Palo Alto: Consulting Psychologists Press.

*Mathad, M. D., Pradhan, B., \& Sasidharan, R. K. (2017). Effect of yoga on psychological functioning of nursing students: A randomized wait list control trial. Journal of Clinical and Diagnostic Research: JCDR, 11(5), $\mathrm{KC} 01$.

McVicar, A. (2003). Workplace stress in nursing: A literature review. Journal of Advanced Nursing, 44(6), 633-642.

Mills, A., Gilbert, P., Bellew, R., McEwan, K., \& Gale, C. (2007). Paranoid beliefs and self-criticism in students. Clinical Psychology \& Psychotherapy, 14(5), 358-364.

Moher, D., Liberati, A., Tetzlaff, J., Altman, D. G., \& The PRISMA Group. (2009). Preferred reporting items for systematic reviews and meta-analyses: The PRISMA statement. PLoS Medicine, 6(7).
Morris, S. P., \& DeShon, R. P. (2002). Combining effect size estimate in meta-analysis with repeated measures and independent-groups designs. Psychological Methods, 7, 105-125.

Murphy, R. J., Gray, S. A., Sterling, G., Reeves, K., \& DuCette, J. (2009). A comparative study of professional student stress. Journal of Dental Education, 73(3), 328-337.

Neff, K. D. (2003). The development and validation of a scale to measure self-compassion. Self and Identity, 2(3), 223-250.

Neff, K. D., \& Dahm, K. A. (2015). Self-compassion: What it is, what it does, and how it relates to mindfulness. In Handbook of mindfulness and self-regulation (pp. 121-137). New York: Springer.

Neff, K., \& Germer, C. (2018). The mindful self-compassion workbook: A proven way to accept yourself, build inner strength, and thrive. Guilford Publications.

Neff, K. D., \& Pommier, E. (2013). The relationship between selfcompassion and other-focused concern among college undergraduates, community adults, and practicing meditators. Self and Identity, 12(2), 160-176.

Neff, K. D., \& Vonk, R. (2009). Self-compassion versus global self-esteem: Two different ways of relating to oneself. Journal of Personality, 77(1), 23-50.

Neff, K. D., Hsieh, Y. P., \& Dejitterat, K. (2005). Self-compassion, achievement goals, and coping with academic failure. Self and Identity, 4(3), 263-287.

Neff, K. D., Rude, S. S., \& Kirkpatrick, K. L. (2007a). An examination of self-compassion in relation to positive psychological functioning and personality traits. Journal of Research in Personality, 41(4), 908-916.

Neff, K. D., Kirkpatrick, K. L., \& Rude, S. S. (2007b). Self-compassion and adaptive psychological functioning. Journal of Research in Personality, 41(1), 139-154.

*Pakenham, K. I. (2015). Effects of acceptance and commitment therapy (ACT) training on clinical psychology trainee stress, therapist skills and attributes, and ACT processes. Clinical Psychology \& Psychotherapy, 22(6), 647-655.

Pastore, F. R., Gambert, S. R., Plutchik, A., \& Plutchik, R. (1995). Empathy training for medical students. Unpublished manuscript, New York Medical College.

*Penque, S. (2009). Mindfulness based stress reduction effects on registered nurses. (Unpublished doctoral dissertation). University of Minnesota, Minneapolis.

Piet, J., \& Hougaard, E. (2011). The effect of mindfulness-based cognitive therapy for prevention of relapse in recurrent major depressive disorder: A systematic review and meta-analysis. Clinical Psychology Review, 31(6), 1032-1040.

Poghosyan, L., Clarke, S. P., Finlayson, M., \& Aiken, L. H. (2010). Nurse burnout and quality of care: Cross-national investigation in six countries. Research in Nursing \& Health, 33, 288-298.

*Raab, K., Sogge, K., Parker, N., \& Flament, M. F. (2015). Mindfulnessbased stress reduction and self-compassion among mental healthcare professionals: A pilot study. Mental Health, Religion \& Culture, 18(6), 503-512.

Raes, F., Pommier, E., Neff, K. D., \& Van Gucht, D. (2011). Construction and factorial validation of a short form of the Self-Compassion Scale. Clinical Psychology \& Psychotherapy, 18(3), 250-255.

*Rao, N., \& Kemper, K. J. (2017). Online training in specific meditation practices improves gratitude, well-being, self-compassion, and confidence in providing compassionate care among health professionals. Journal of Evidence-Based Complementary \& Alternative Medicine, 22(2), 237-241.

Regehr, C., Glancy, D., Pitts, A., \& LeBlanc, V. R. (2014). Interventions to reduce the consequences of stress in physicians: A review and meta-analysis. The Journal of Nervous and Mental Disease, 202(5), 353-359.

Richardson, D. A., Jaber, S., Chan, S., Jesse, M. T., Kaur, H., \& Sangha, R. (2016). Self -compassion and empathy: Impact on burnout and 
secondary traumatic stress in medical training. Open Journal of Epidemiology, 6, 161-166.

*Rimes, K. A., \& Wingrove, J. (2011). Pilot study of mindfulness-based cognitive therapy for trainee clinical psychologists. Behavioural and Cognitive Psychotherapy, 39(2), 235-241.

*Rodrigues, N. P., Cohen, L. L., McQuarrie, S. C., \& Reed-Knight, B. (2018). Burnout in nurses working with youth with chronic pain: A pilot intervention. Journal of Pediatric Psychology, 43(4), 382-391.

*Romcevich, L. E., Reed, S., Flowers, S. R., Kemper, K. J., \& Mahan, J. D. (2018). Mind-body skills training for resident wellness: A pilot study of a brief mindfulness intervention. Journal of Medical Education and Curricular Development, 5, 2382120518773061.

Rosen, I. M., Gimotty, P. A., Shea, J. A., \& Bellini, L. M. (2006). Evolution of sleep quantity, sleep deprivation, mood disturbances, empathy, and burnout among interns. Academic Medicine, 81, 8285.

Rosenberg, M. S. (2005). The file-drawer problem revisited: A general weighted method for calculating fail-safe numbers in meta-analysis. Evolution, 59(2), 464-468.

Rosenberg MS, Adams DC, Gurevitch J (2000). MetaWin: Statistical Software for MetaAnalysis Version 2. Sunderland, MA: Sinauer Associates. URL http://www.metawinsoft.com/.

*Runyan, C., Savageau, J. A., Potts, S., \& Weinreb, L. (2016). Impact of a family medicine resident wellness curriculum: A feasibility study. Medical Education Online, 21(1), 30648.

Rutledge, T., Stucky, E., Dollarhide, A., Shively, M., Jain, S., Wolfson, T., et al. (2009). A real-time assessment of work stress in physicians and nurses. Health Psychology, 28(2), 194-200.

*Scarlet, J., Altmeyer, N., Knier, S., \& Harpin, R. E. (2017). The effects of compassion cultivation training (CCT) on health-care workers. Clinical Psychologist, 21(2), 116-124.

Shanafelt, T., \& Dyrbye, L. (2012). Oncologist burnout: causes, consequences, and responses. Journal of Clinical Oncology, 30, 12351241.

Shanafelt, T. D., Bradley, K. A., Wipf, J. E., \& Back, A. L. (2002). Burnout and self-reported patient care in an internal medicine residency program. Annals of Internal Medicine, 136(5), 358-367.

Shanafelt, T. D., Boone, S., Tan, L., et al. (2012). Burnout and satisfaction with work-life balance among US physicians relative to the general US population. Archives of Internal Medicine, 172(18), 1377-1385.

Shanafelt, T., Hasan, O., Dyrbye, L., Sinsky, C., Satele, D., Sloan, J., \& West, C. (2015). Changes in burnout and satisfaction with work-life balance in physicians and the general US working population between 2011 and 2014. Mayo Clinic Proceedings, 90(12), 16001613.

Shapiro, S. L., Astin, J. A., Bishop, S. R., \& Cordova, M. (2005). Mindfulness-based stress reduction for health care professionals: Results from a randomized trial. International Journal of Stress Management, 12(2), 164-176.

Shapiro, S. L., Brown, K. W., \& Biegel, G. M. (2007). Teaching self-care to caregivers: Effects of mindfulness-based stress reduction on the mental health of therapists in training. Training and education in professional psychology, 1(2), 105-115.

*Slatyer, S., Craigie, M., Heritage, B., Davis, S., \& Rees, C. (2017). Evaluating the effectiveness of a brief mindful self-care and resiliency (MSCR) intervention for nurses: A controlled trial. Mindfulness, 9(2), 534-546.

Smith, L. J. W., \& Beretvas, S. N. (2009). Estimation of the standardized mean difference for repeated measures designs. Journal of Modern Applied Statistical Analyses, 8, 600-609.

Spickard Jr., A., Gabbe, S. G., \& Christensen, J. F. (2002). Mid-career burnout in generalist and specialist physicians. JAMA, 288(12), $1447-1450$.

Stafford-Brown, J., \& Pakenham, K. I. (2012). The effectiveness of an ACT informed intervention for managing stress and improving therapist qualities in clinical psychology trainees. Journal of Clinical Psychology, 68(6), 592-513.

Stewart, S. M., Betson, C., Lam, T. H., Marshall, I. B., Lee, P. W. H., \& Wong, C. M. (1997). Predicting stress in first year medical students: A longitudinal study. Medical Education, 31(3), 163-168.

Stucky, E. R., Dresselhaus, T. R., Dollarhide, A., Shively, M., Maynard, G., Jain, S., et al. (2009). Intern to attending: Assessing stress among physicians. Academic Medicine, 84(2), 251-257.

The jamovi Project. (2019). jamovi. (Version 1.0) [Computer Software]. Retrieved from www.jamovi.org.

Vahey, D. C., Aiken, L. H., Sloane, D. M., Clarke, S. P., \& Vargas, D. (2004). Nurse burnout and patient satisfaction. Medical Care, $42(2$ Suppl), 1157-1166.

Verdon, M., Merlani, P., Perneger, T., \& Ricou, B. (2008). Burnout in a surgical ICU team. Intensive Care Medicine, 34, 152-156.

*Verweij, H., van Ravesteijn, H., van Hooff, M. L., Lagro-Janssen, A. L., \& Speckens, A. E. (2017). Mindfulness-based stress reduction for residents: A randomized controlled trial. Journal of General Internal Medicine, 33(4), 429-436.

Wallace, J. E., Lemaire, J. B., \& Ghali, W. A. (2009). Physician wellness: A missing quality indicator. The Lancet, 374(9702), 1714-1721.

West, C. P., Dyrbye, L. N., Erwin, P. J., \& Shanafelt, T. D. (2016). Interventions to prevent and reduce physician burnout: A systematic review and meta-analysis. The Lancet, 388(10057), 2272-2281.

Wiklund Gustin, L., \& Wagner, L. (2013). The butterfly effect of caringclinical nursing teachers' understanding of self-compassion as a source to compassionate care. Scandinavian Journal of Caring Sciences, 27(1), 175-183.

Williams, E. S., Manwell, L. B., Konrad, T. R., \& Linzer, M. (2007). The relationship of organizational culture, stress, satisfaction, and burnout with physician-reported error and suboptimal patient care: Results from the MEMO study. Health Care Management Review, 32(3), 203-212.

Williams, J. G., Stark, S. K., \& Foster, E. E. (2008). Start today or the very last day? The relationships among self-compassion, motivation, and procrastination. American Journal of Psychological Research, 4, $37-44$.

Smith, L. J., \& Beretvas, S. N. (2009). Estimation of the standardized mean difference for repeated measures designs. Journal of Modern Applied Statistical Analyses, 8, 600-609.

Publisher's Note Springer Nature remains neutral with regard to jurisdictional claims in published maps and institutional affiliations. 